\title{
INFLUENCIA DA ESTRUTURA DE CAPITAL NOS INVESTIMENTOS EM INOVAÇÃO DAS INDÚSTRIAS LISTADAS NA BM\&FBOVESPA
}

\section{1- Rafael Sales Almendra*}

Mestre em Administração e Controladoria pela Universidade Federal do Ceará (UFC), Brasil.

Departamento de Administração - Instituto Federal de Educação, Ciência e Tecnologia do Piauí (IFPI), Brasil rafael.almendra@ifpi.edu.br

http://lattes.cnpq.br/3445859953494127

\section{2- Alessandra Carvalho de Vasconcelos}

Doutora em Engenharia de Produção pela Universidade Federal de Santa Catarina (UFSC), Brasil.

Programa de Pós-Graduação em Administração e Controladoria - Universidade Federal do Ceará (PPAC/UFC), Brasil. alevasconcelos.ufc@gmail.com http://lattes.cnpq.br/3674132552801030

\section{3- Rayane Nogueira Aragão}

Graduanda em Ciências Contábeis pela Universidade Federal do Ceará (UFC), Brasil.

Departamento de Contabilidade - Universidade Federal do Ceará (UFC), Brasil.

aragao_rayane@hotmail.com

http://lattes.cnpq.br/3676414063502292

\section{4- Ione Azevedo Cysne}

Graduanda em Ciências Contábeis pela Universidade Federal do Ceará (UFC), Brasil.

Departamento de Contabilidade - Universidade Federal do Ceará (UFC), Brasil.

ionecysne@gmail.com

http://lattes.cnpq.br/0020103818326240

Diego Maganhotto Coraiola - Editor Geral

Editor responsável pela submissão:

Diego Maganhotto Coraiola.

Artigo analisado via processo de revisão duplo cego (Double-blind).

Recebido em: 31/01/2017

Aprovado em: 05/04/2017

última Alteração: 03/08/2017

* Contato Principal: Av. Odilon Araújo, 1760. Piçarra, Teresina - PI. CEP: 64017-280 


\title{
INFLUÊNCIA DA ESTRUTURA DE CAPITAL NOS INVESTIMENTOS EM INOVAÇÃO DAS INDÚSTRIAS LISTADAS NA BM\&FBOVESPA ${ }^{1}$
}

\section{RESUMO}

Analisou-se a influência da estrutura de capital nos investimentos em inovação de 120 indústrias listadas na BM\&FBovespa no período de 2013 a 2015. Como proxies para estrutura de capital, consideraram-se os endividamentos de curto prazo, de longo prazo e total. Para representar os investimentos em inovação, utilizou-se o número de patentes registradas e o percentual dos gastos com $P \& D$ em relação às vendas. Através do Teste LSD de Fischer, foi possível constatar que as empresas que não investem em inovação possuem endividamento superior. Por meio da regressão linear com dados em painel, verificou-se que somente os endividamentos de longo prazo e total influenciam positivamente os investimentos em inovação via patentes. Assim, os resultados sugerem que os recursos próprios podem ser insuficientes para investimentos em inovação, levando os recursos de terceiros a contribuir para o aumento dos investimentos em inovação via registro de patentes, conforme preconiza a Teoria Pecking Order, bem como colaborar para a redução dos custos de agência, limitando a atuação dos gestores, como proposto pela Teoria da Agência.

\section{Palavras-chave}

Estrutura de capital; Investimentos em inovação; Teoria Pecking Order; Teoria da Agência.

\section{INFLUENCE OF THE CAPITAL STRUCTURE IN THE INVESTMENTS IN INNOVATION OF THE INDUSTRIES LISTED ON THE BM\&FBOVESPA}

\begin{abstract}
In this study the influence of the capital structure in the investments in innovation of 120 industries listed on the BM\&FBovespa was analyzed in the period from 2013 to 2015. As proxies for capital structure, we consider short-term, long-term and total debt. In order to represent the investments in innovation, the number of registered patents and the percentage of expenditure in with $R \& D$ in relation to sales were considered. Through the Fischer LSD Test, it was possible to verify that companies that do not invest in innovation have higher debts. Through linear regression with panel data, it was verified that only the long-term and total debts have a positive influence on innovation investments through patents. Therefore, the results suggest that own resources may be insufficient to investments in innovation, leading third parties resources to contribute to the increase of investments in innovation through patent registration as stated by the Pecking Order Theory, as well as to collaborate to the reduction of agency costs, limiting the role of the managers, as proposed by the Agency Theory.
\end{abstract}

\section{Keywords}

Capital structure; Investments in innovation; Pecking Order Theory; Agency Theory. 


\section{Introdução}

Dentre as temáticas objeto de intensa discussão em finanças, mesmo com forte apoio teórico e empírico, destaca-se a estrutura de capital, sendo a maior questão a inexistência de uma estrutura de capital ótima nas empresas (Kayo \& Famá, 2004). Entende-se por estrutura de capital a maneira como as firmas utilizam suas fontes de financiamento com o intuito de promover os investimentos pretendidos (Assaf, 2014; Harris \& Raviv, 1991; O'Brien, 2003). Em outras palavras, a estrutura de capital é a forma como as firmas criam um mix para utilizar recursos, próprios e/ou de terceiros, com a finalidade de financiar ativos e desenvolver seus investimentos (Teixeira, Nossa, \& Funchal, 2011).

Com a dinamicidade dos mercados, as empresas passam a valorizar ainda mais os recursos de que dispõem. Dentre esses recursos, destacam-se os ativos intangíveis, os quais são utilizados para a maximização do valor econômico da firma, bem como para a criação de vantagem competitiva (Santos, Vasconcelos, \& Luca, 2013; Santos, Hoffmann, Jara, \& Coral, 2014).

Dentre as estratégias organizacionais, sobressai a inovação, que é utilizada quando se pretende produzir, adotar, assimilar ou explorar uma novidade que vai acrescentar valor aos macroambientes econômico e social da empresa (Crossan \& Apaydin, 2010), além de ampliar sua competitividade (Crisóstomo, López-Iturriaga, \& Vallelado, 2011).

Uma empresa que pretende explorar oportunidades por meio das estratégias de inovação pode não dispor dos recursos necessários para cobrir o custo dos investimentos pretendidos, restringindo, assim, o alcance de seus objetivos (Bartoloni, 2013). Analisando esse cenário, O'Brien (2003) afirma que a escassez leva a empresa a optar por uma estrutura de capital que atenda às estratégias em questão, já que esse construto pode ser considerado uma fonte de criação de valor estratégico.

Dentre as teorias que fundamentam as investigações sobre estrutura de capital, destacam-se: a Trade-Off, que propõe a existência de uma estrutura de capital ótima e menciona que as firmas buscam níveis de dívida que balanceiam benefícios fiscais e custos de dificuldades financeiras (Miller, 1977; Myers, 1984); a Market Timing, a qual refere-se à prática oportunista de emissão de ações quando elas estão valorizadas e recompra a preços baixos, fato esse que afeta a política de financiamento das empresas (Baker \& Wurgler, 2002); a_Pecking Order, segundo a qual as empresas possuem uma hierarquia de fontes de financiamento, na qual o gestor decide sobre a estrutura mais adequada, em que um tipo de financiamento é preferível a outros (Myers, 1977; Myers, 1984); e a Teoria da Agência, a qual é pautada na relação principal e agente, na qual o agente, ao se deparar com maior volume de fluxo de caixa livre, tende a investir recursos excedentes em projetos que não remunerem o capital investido, o que culmina com o desejo do principal em diminuir o fluxo de caixa livre, levando os agentes a incorrerem em dívidas, as quais possuem capacidade/potencial para reduzir a aplicação de recursos discricionários por parte do gestor (Kayo \& Fama, 2004).

Diante do exposto e levando-se em conta que a maneira como as firmas financiam suas estratégias é capaz de direcionar os investimentos institucionais (O'Brien, 2003; Williamson, 1988) e que, para serem implementadas, as estratégias de inovação requerem investimentos (Acs \& Isberg, 1991), a pesquisa norteia-se pela seguinte questão: Qual a influência da estrutura de capital nos investimentos em inovação?

Como a estrutura de capital gera impacto sobre a escolha das estratégias, especialmente em empresas preocupadas com inovação (Yuke \& Xiaomin, 2015) e aquelas detentoras de estrutura de capital com baixos níveis de dívida são mais propensas a desenvolver e utilizar as capacidades inovadoras ( $\mathrm{Li} \&$ Simerly, 2002), conjectura-se, então, um relacionamento entre a estrutura de capital e investimentos em inovação (Canto \& Gonzalez, 1999; Dalziel, Gentry, \& Bowerman, 2011; Lai, Lin, \& Lin, 2015). Assim, formula-se a seguinte hipótese de pesquisa: A estrutura de capital da empresa influencia os investimentos em inovação.

O estudo tem como objetivo geral analisar a influência da estrutura de capital nos investimentos em inovação nas indústrias listadas na Bolsa de Valores, Mercadorias e Futuros (BM\&FBovespa). Tem ainda os seguintes objetivos específicos: (i) traçar o perfil dos investimentos em inovação nas empresas e (ii) comparar a estrutura de capital nas empresas inovadoras com aquela adotada pelas empresas não inovadoras.

Para tanto, o estudo utiliza uma amostra de 120 indústrias listadas na BM\&FBovespa, considerando-se o triênio 2013 a 2015. As proxies para estrutura de capital são: endividamento de curto prazo, endividamento de longo prazo e endividamento total. Para os investimentos em inovação, considera-se como proxies o valor do dispêndio com P\&D e a quantidade de patentes registradas em cada ano do período sob análise. 
Diante da relevância dos temas, Abreu, Bruni, Gomes e Paixão (2015), Acs e Isberg (1991), Bartoloni (2013), Blass e Yosha (2003), Kayo e Famá (2004), Li e Simerly (2002), Magri (2009) e O'Brien (2003) investigaram o relacionamento entre estrutura de capital e inovação. Apesar das importantes contribuições desses estudos, os mesmos não apontam um consenso a respeito do relacionamento dos temas em seus resultados, tampouco são convergentes quanto ao alinhamento com uma teoria sobre estrutura de capital. Também é importante destacar que a maioria desses estudos se centra na análise de firmas de mercados desenvolvidos, assim, não considera firmas atuantes em mercado em crescimento, que é o caso do Brasil. Além disso, a investigação aqui apresentada não considera somente os índices tradicionais de estrutura de capital, mas traz à tona a capacidade da empresa em gerar caixa, por meio da análise da margem EBITDA - Lucro antes de Juros, Impostos, Depreciação e Amortização (Assaf, 2014; Bach, 2013; Soares, Coutinho, \& Camargos, 2013).

Assim, investiga-se aqui a influência da estrutura de capital nos investimentos em inovação nas indústrias listadas na BM\&FBovespa, de modo a subsidiar tanto o meio empresarial, quanto o acadêmico, já que contribui para aumentar a oferta de estudos sobre as temáticas estrutura de capital e inovação, ainda incipientes no Brasil, bem como auxilia os gestores a decidir sobre a maneira de combinar as fontes de financiamento, o que constitui decisão de extrema importância no contexto financeiro das firmas.

\section{Quadro Teórico}

\subsection{Correntes Teóricas da Estrutura de Capital}

Define-se estrutura de capital como a forma por meio da qual a empresa utiliza as fontes de recursos disponíveis para aplicá-los em suas atividades (Camilo, Xavier, Bandeira-de-Mello, \& Marcon, 2010). Essa estrutura diz respeito ao modo como a empresa utiliza o capital próprio e o capital de terceiros para financiar seus ativos, sendo o capital próprio entendido como o montante de recursos pertencentes aos sócios ou acionistas e por eles fornecidos, enquanto o capital de terceiros advém de recursos externos, obtidos através de dívidas contraídas com credores específicos (Brito, Corrar, \& Batistella, 2007). Campara, Vieira e Ceretta (2016, p. 6) advertem que a compreensão dos aspectos inerentes ao endividamento é um tema bastante discutido na academia, contudo, "são poucos os estudos que relacionam aspectos comportamentais e socioeconômicos à atitude ao endividamento".

A temática aqui discutida fundamenta-se em teorias, as quais permitem prever como a gestão da empresa vai agir em relação às escolhas de financiamento. As teorias sobre estrutura de capital começaram a ser formuladas por Modigliani e Miller (1958), segundo os quais o capital pode ser obtido por diferentes meios, variando, assim, a composição da dívida. Os autores demonstram que a estrutura de capital escolhida não afeta o valor da empresa, já que este depende da qualidade dos ativos (investimentos), e não da maneira como ela se financia (Modigliani \& Miller, 1958). Essa é a denominada Teoria da Irrelevância da Estrutura de Capital - Modelo MM.

Outras teorias foram criadas e são utilizadas para fundamentar o tema estrutura de capital, destacando-se a Teoria do Trade-off, a Teoria Pecking Order (Hierarquização), a Teoria da Agência e a Market Timing Theory.

A Teoria Trade-off propõe a existência de uma estrutura de capital ótima, e menciona que as firmas buscam níveis de dívida que balanceiam benefícios fiscais e custos de dificuldades financeiras. Assim, quanto mais lucrativa for a empresa, mais lucro tributável ela deve proteger, além de ser mais intenso o uso de dívidas como fonte de financiamento, haja vista o benefício fiscal obtido por meio dessa forma de captação (Alves, Couto, \& Francisco, 2015; Christensen, Flor, Lando, \& Miltersen, 2014; Miller, 1977; Myers, 1984).

Segundo a Teoria Pecking Order, de Myers e Majluf (1984), existe uma hierarquia ou preferência por fontes de financiamento a serem utilizadas nos investimentos. Primeiramente, a firma financia seus projetos com a utilização de recursos internos, através da retenção de lucros. Se os recursos não forem suficientes, a empresa optaria pelo financiamento externo, por meio da dívida, e, em último caso, emitiria ações, o que não é desejável pelos shareholders, pois essa emissão reflete o valor da ação da companhia (Alves et al., 2015; Florackis, Kanas, \& Kostakis, 2015; Myers \& Majluf, 1984; Nhung \& Okuda, 2015).

Já a Teoria da Agência, proposta por Jensen e Meckling (1976), analisa a relação entre agente e principal, bem como os custos respectivos. A relação é caracterizada como um contrato, em que os acionistas (principal) contratam um profissional (agente) para realizar serviços para aqueles. 
Entretanto, dessa relação podem advir os conflitos de agência, já que ambas as partes desejam maximizar sua utilidade, o que pode levar o agente a tomar decisões em benefício próprio (Jensen \& Meckling, 1976). Para diminuir esses conflitos, o principal incorre em custos de agência, para verificar se o agente agiu no sentido de atender a interesses pessoais (Arosa, Richie \& Schuhmann, 2014; Jensen \& Meckling, 1976; Joliet \& Muller, 2013), uma vez que ao se deparar com maior volume de fluxo de caixa livre, maior é a tendência do gestor em investir recursos excedentes em projetos que não remunerem o capital investido (Kayo \& Fama, 2004).

Vale ressaltar que a dívida tem capacidade/potencial para reduzir os custos de agência, pois através dela há uma diminuição do fluxo de caixa livre, reduzindo os gastos a critério do agente, que, dispondo de poucos recursos livres, deverá utilizá-los da melhor forma possível, influenciando a estrutura de capital (Frank \& Goyal, 2003; Jensen \& Meckling, 1976). Em outras palavras, Medeiros e Daher (2008, p. 184) explicam que, para mitigar "os problemas de agência, as empresas emitiriam mais dívida, já que a obrigação do pagamento das dívidas levaria os gerentes a serem mais cuidadosos com os recursos da empresa e a não os utilizarem em causa própria".

Recentemente, a Teoria Market Timing entrou em pauta na seara da discussão sobre estrutura de capital. Desenvolvida por Baker e Wurgler (2002), a referida teoria preconiza que as políticas sobre o financiamento das empresas são relevantes, pois o preço do capital é a principal variável que influencia a decisão sobre a emissão de novas ações, em que os acionistas são beneficiados quando o preço das ações está baixo e são prejudicados em momentos em que o preço de mercado está subvalorizado. Em essência, a Market Timing refere-se à prática oportunista de emissão de ações quando elas estão valorizadas e recompra a preços baixos, pois assim, explora-se flutuações temporárias no custo de capital próprio (Alves et al., 2015; Alti, 2006; Arosa et al., 2014; Bolton, Chen, \& Wang, 2013).

Nota-se que todas as teorias que embasam o estudo da estrutura de capital de alguma forma contribuem para o estudo sobre decisões de financiamento. Entretanto, importa mencionar que não há um consenso sobre qual teoria explica melhor os determinantes da estrutura de capital (Campos \& Nakamura, 2013; Correa, Basso, \& Nakamura, 2013).

Destarte, a maneira como os gestores da firma combinam as fontes de financiamento constitui uma decisão de grande importância, tanto no contexto financeiro, quanto no contexto estratégico (Camilo et al., 2010), haja vista que os investimentos em inovação, por vezes, demandam fundos que geralmente a empresa não possui (Crisóstomo, 2009).

\subsection{Investimentos em Inovação: P\&D e Patentes}

Segundo Zaltman, Duncan e Holbek (1973), inovação é definida por uma ideia, uma prática ou um artefato material percebido como novo, relevante e único, adotado em determinado processo, área ou por toda a organização. Freeman e Soete (2008) conceituam inovação como a inclusão de uma técnica, design, fabricação, gerenciamento e atividades comerciais pertinentes ao marketing de um produto ou do primeiro uso comercial de um processo ou equipamento, sejam eles novos ou incrementados.

Conforme o Manual de Oslo (OECD, 2005), inovação é definida como a implementação de um produto (bem ou serviço) novo ou significativamente melhorado, ou um processo, ou um novo método de marketing, ou um novo método organizacional nas práticas de negócios, na organização do local de trabalho ou nas relações externas. Nesse sentido, entende-se que a inovação significa a quebra de padrões, constituindo-se como ações empresariais, com focos interno e externo.

Assim, ao vislumbrar oportunidades, colocam-se em prática ações empresariais tais como a aplicação de recursos, os quais, se investidos de forma eficiente, ajudam a atingir os resultados desejados e proporcionam a elevação do nível de competitividade (Dai, Maksimov, Gilbert, \& Fernhaber, 2014; Knight \& Liesh, 2016).

Como a busca por competitividade é cada dia mais atrelada aos ativos intangíveis (Gibson \& Naquin, 2011; Vargas, 2015), existe a predominância de investimentos centrados na inovação, como meio de promoção da competitividade (Burlamaqui \& Proença, 2003; Gifford, 1992). Teh, Kayo e Kimura (2008) ratificam que um importante ativo intangível é a inovação, já que ela gera vantagens competitivas, as quais possibilitam a construção de barreiras contra ameaças do mercado. Assim, a busca por vantagem competitiva tem sido cada vez mais requisitada pelas empresas, principalmente pelo fato de as inovações serem criadas, inicialmente, por investimentos em ativos intangíveis (Lev, 2001). 
Diante do exposto, percebe-se que a competitividade está relacionada à aplicação de recursos de caráter intangível, destacando-se os ativos intangíveis de inovação. Assim, o presente estudo considera como proxys para os investimentos em inovação as patentes, pelo fato dessas demandarem a realização de investimentos para sua concessão e seu registro, e os investimentos com pesquisa e desenvolvimento (P\&D), pois os mesmos são esforços empregados nas firmas para gerar inovação, visando ampliar sua competitividade (Pavitt, 1982; Santos et al., 2014).

A inovação via patentes ocorre através de uma concessão que confere à empresa a exclusividade de exploração, impedindo a produção e o uso de produtos e/ou processos por terceiros durante determinado período (Allred \& Park, 2007; Teh et al., 2008), configurando um monopólio temporário com o objetivo de estimular novas invenções, para o posterior progresso tecnológico, continuidade e viabilidade da firma (Griliches, 1990).

Já os investimentos com P\&D relacionam-se com a capacidade de inovação da firma, proporcionando viabilização de projetos que ela objetiva desenvolver e que, por conseguinte, incrementam as vendas e impulsionam os seus resultados econômicos (Ramos \& Zilber, 2015).

Devido a sua grande relevância, a inovação empresarial tem sido bastante discutida no meio acadêmico, ganhando destaque em diferentes enfoques, como, por exemplo, a correlação com a estrutura de capital (Abreu et al., 2015; Bartoloni, 2013; Blass \& Yosha, 2003; Kayo \& Famá, 2004). Com abordagens diferentes acerca da inovação, diversos estudos ratificam a importância da inovação como fator capaz de propiciar vantagem competitiva.

Abreu et al. (2015) analisaram a relação entre inovação tecnológica e estrutura de capital nas firmas brasileiras, concluindo que há relação direta entre estrutura de capital e gastos com P\&D e que não ocorre correlação quando a proxy para a inovação são as patentes.

Após analisar a relação entre restrições financeiras e inovação no mercado italiano, Bartoloni (2013) constatou que as restrições de crédito afetam as empresas inovadoras de menor porte e que estas utilizam fundos internos, em vez de dívidas, para financiar suas estratégias de inovação; ou seja, o autor não encontrou nenhuma relação entre os dois construtos.

Analisando empresas israelenses, Blass e Yosha (2003) identificaram que os padrões de financiamento daquelas que investem intensivamente em P\&D são diferentes daqueles observados nas demais. $O$ estudo indicou que os investimentos em P\&D tendem a ser financiados com recursos gerados na própria firma.

Objetivando mostrar evidências de que as empresas intangível-intensivas apresentam diferenças significativas em relação às empresas tangível-intensivas no que diz respeito à estrutura de capital e ao risco, Kayo e Famá (2004) concluíram que as empresas intensivas em ativos intangíveis apresentam, em média, nível mais baixo de endividamento, pelo fato de utilizarem maior volume de capital próprio em seus investimentos.

Nos estudos empíricos citados, nota-se que muitos deles desenvolveram a análise das temáticas em contextos sociais e econômicos desenvolvidos, o que ratifica a análise aqui proposta num país emergente, no caso o Brasil. Ressalta-se também que apesar das importantes contribuições desses estudos, os mesmos não apontam um consenso a respeito do relacionamento dos temas em seus resultados e tampouco apontam um alinhamento singular com alguma teoria da estrutura de capital.

\section{Procedimentos Metodológicos}

A população da pesquisa compreende as 143 indústrias brasileiras listadas na Bolsa de Valores, Mercadorias e Futuros (BM\&FBovespa) em 2 de maio de 2016. Optou-se pelas indústrias devido à grande representatividade do setor na economia do país, correspondendo a 22,7\% do Produto Interno Bruto - PIB, segundo o Instituto Brasileiro de Geografia e Estatística - IBGE (2016), além de se pressupor que seja um dos que mais realizam investimentos em inovação, buscando vantagem competitiva por ter uma estreita relação com o desenvolvimento tecnológico.

A seleção da amostra considerou as indústrias que disponibilizaram informações durante os exercícios de 2013, 2014 e 2015. A opção pelo triênio deve-se a recomendação contida no Manual de Oslo, para que as pesquisas sobre inovação considerem a análise em relação a um determinado triênio, com o intuito de garantir a veracidade dos dados (OECD, 2005). Além disso, o triênio analisado leva em consideração os três anos mais recentes à data de elaboração da pesquisa. Como 23 indústrias não disponibilizavam as informações referentes a um ou mais exercícios, a amostra ficou delimitada em 120 firmas. 
No estudo, a proxy estrutura de capital foi mensurada por meio dos endividamentos de curto prazo, de longo prazo e total. Para tanto, foram utilizadas informações referentes aos valores dos passivos (Circulante, Não Circulante e total), extraídas das demonstrações financeiras padronizadas (DFP) disponíveis no website da BM\&FBovespa. Em seguida, dividiu-se o valor de cada um dos passivos pelo valor total do Ativo, resultando nos endividamentos de curto prazo, de longo prazo e total, assim como realizado por Póvoa e Nakamura (2015).

Os investimentos em inovação foram analisados por meio do registro de patentes e dos dispêndios com $P \& D$. As informações sobre patentes foram extraídas do website Espacenet, que disponibiliza dados de patentes de diversos organismos no mundo, tais como o Escritório de Patentes Europeu (EPO), o Escritório Norte-Americano de Patentes (USPTO) e inclusive do Instituto Nacional de Propriedade Intelectual (INPI), do Brasil. Assim, verificou-se, através do nome de cada empresa da amostra, o total de patentes registradas em cada um dos três exercícios. A escolha dessa variável se deu pelo fato da existência de um investimento que propicie o registro dessas patentes.

No tocante aos dispêndios com $P \& D$, pesquisou-se o montante despendido para o referido investimento evidenciado nas Notas Explicativas das demonstrações financeiras de cada firma, considerando o período de análise. Adicionalmente, dividiu-se o valor do dispêndio pelo valor da receita líquida de vendas, também disponibilizado nas Notas Explicativas, obtendo-se, assim, o Índice de Inovação (IINOV).

A Figura 1 apresenta as variáveis, as métricas, as fontes de coleta e o suporte teórico utilizados na pesquisa.

Figura 1. Variáveis utilizadas no estudo

\begin{tabular}{|c|c|c|c|c|}
\hline & Variável & Métrica & Fonte de coleta & Suporte teórico \\
\hline \multirow{2}{*}{ 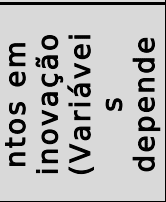 } & $\begin{array}{c}\text { Índice de inovação } \\
\text { (IINOV) }\end{array}$ & $\begin{array}{l}\text { Razão entre o valor dos } \\
\text { dispêndios com P\&D e o da } \\
\text { receita líquida de vendas }\end{array}$ & $\begin{array}{l}\text { DFP - Notas } \\
\text { Explicativas }\end{array}$ & $\begin{array}{l}\text { Baumann e Kritikos (2016) } \\
\text { Li e Simerly (2002) } \\
\text { Yuke e Xiaomin (2015) }\end{array}$ \\
\hline & Patentes (PAT) & $\begin{array}{l}\text { Ln do total de patentes } \\
\text { concedidas no período }\end{array}$ & Website Espacenet & $\begin{array}{l}\text { Kayo, Teh e Basso (2006) } \\
\text { Moura e Galina (2009) } \\
\text { Teh, Kayo e Kimura (2008) }\end{array}$ \\
\hline \multirow{3}{*}{ 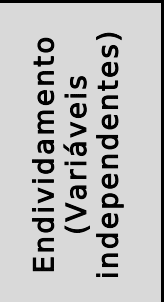 } & $\begin{array}{l}\text { Endividamento de } \\
\text { Curto Prazo (ECP) }\end{array}$ & Passivo Circulante / Ativo & DFP & $\begin{array}{l}\text { Brito et al. (2007) } \\
\text { Póvoa e Nakamura (2015) } \\
\text { Segura e Formigoni (2014) }\end{array}$ \\
\hline & $\begin{array}{l}\text { Endividamento de } \\
\text { Longo Prazo (ELP) }\end{array}$ & Passivo Não Circulante / Ativo & DFP & $\begin{array}{l}\text { Brito et al. (2007) } \\
\text { Póvoa e Nakamura (2015) } \\
\text { Segura e Formigoni (2014) }\end{array}$ \\
\hline & $\begin{array}{l}\text { Endividamento } \\
\text { Total (ETO) }\end{array}$ & $\begin{array}{c}\text { (Passivo Circulante + Passivo } \\
\text { Não Circulante) / Ativo }\end{array}$ & DFP & $\begin{array}{l}\text { Póvoa e Nakamura (2015) } \\
\text { Segura e Formigoni (2014) } \\
\text { Soares e Kloeckner (2008) }\end{array}$ \\
\hline \multirow{5}{*}{ 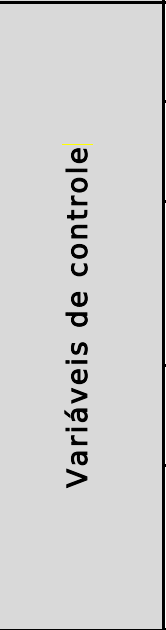 } & $\begin{array}{l}\text { Margem EBITDA } \\
\text { (EBITDA) }\end{array}$ & $\begin{array}{c}\text { EBITDA / Receita líquida de } \\
\text { vendas }\end{array}$ & $\begin{array}{l}\text { DFP - Notas } \\
\text { Explicativas }\end{array}$ & \begin{tabular}{|l|} 
Bach (2013) \\
Guo, Hotchkiss e Song (2011) \\
Soares et al. (2013) \\
\end{tabular} \\
\hline & $\begin{array}{l}\text { Rentabilidade } \\
\quad \text { (ROE) }\end{array}$ & $\begin{array}{l}\text { Lucro Líquido / Patrimônio } \\
\text { Líquido }\end{array}$ & DFP & $\begin{array}{l}\text { Brito, Brito e Morganti (2009) } \\
\text { Gonçalves, Veit e Monteiro (2013) } \\
\text { Santos, Calíope e Silva Filho (2016) }\end{array}$ \\
\hline & Tamanho (TAM) & Ln do Ativo & DFP & $\begin{array}{l}\text { Boehe, Larentis, Toni e Mattia } \\
\text { (2011) } \\
\text { Kayo et al. (2006) } \\
\text { Shearmur, Doloreux e Laperrière } \\
\text { (2014) }\end{array}$ \\
\hline & Idade (IDADE) & Idade da empresa & $\begin{array}{c}\text { Formulário de } \\
\text { Referência - Dados } \\
\text { gerais } \\
\end{array}$ & $\begin{array}{l}\text { McDougall e Oviatt (2000) } \\
\text { Santos, Vasconcelos e Luca (2015) } \\
\text { Shearmur et al. (2014) }\end{array}$ \\
\hline & $\begin{array}{l}\text { Segmento de } \\
\text { listagem da } \\
\text { BM\&FBovespa } \\
\text { (SEG_LIST) }\end{array}$ & $\begin{array}{l}\text { Dummy: } \\
\text { 1, se listada em um dos níveis } \\
\text { diferenciados de governança } \\
\text { corporativa } \\
0 \text {, se não listada }\end{array}$ & $\begin{array}{c}\text { Formulário de } \\
\text { Referência - Dados } \\
\text { gerais }\end{array}$ & $\begin{array}{l}\text { Fonseca, Silveira e Hiratuka (2016) } \\
\text { Silveira e Barros (2008) } \\
\text { Singh e Gaur (2013) }\end{array}$ \\
\hline
\end{tabular}

Fonte: Elaborada pelos autores.

Na pesquisa, os métodos de tratamento e análise dos dados são guiados pelos objetivos específicos do estudo. Então, para atender ao primeiro objetivo específico, realizou-se inicialmente uma análise quanto à utilização de investimentos com inovação. Também foram analisados os valores referentes aos dispêndios com $P \& D$ em comparação com a receita de vendas, assim como a quantidade de patentes registradas por ano pesquisado. Adicionalmente, apresentou-se um ranking com as cinco empresas que mais inovaram de acordo com os investimentos em inovação 
consideradas no estudo. Em seguida, aplicou-se a Análise de Correspondência Múltipla (ACM), buscando-se identificar uma possível associação entre os investimentos em inovação e algumas características da empresa, no caso: rentabilidade, tamanho, idade e segmento de listagem da BM\&FBovespa.

Para atender aos propósitos da ACM, as variáveis tamanho, rentabilidade e idade foram categorizadas de acordo com os quartis de sua distribuição. Dessa maneira, as variáveis foram distribuídas segundo os níveis baixo, médio-baixo, médio-alto e alto, como mostra a Tabela 1.

Tabela 1:

Categorização das variáveis

\begin{tabular}{|l|c|c|c|}
\hline Nível & Tamanho & Rentabilidade & Idade (anos) \\
\hline Baixo & Até 12,6980 & Até $-0,0195$ & Até 29 \\
\hline Médio-baixo & 12,6981 a 14,0195 & $-0,0196$ a 0,0671 & 30 a 55 \\
\hline Médio-alto & 14,0196 a 15,6861 & 0,0672 a 0,1682 & 56 a 75 \\
\hline Alto & Acima de 15,6861 & Acima de 0,1682 & Acima de 75 \\
\hline
\end{tabular}

Fonte: Elaborada pelos autores.

A variável SEG_LIST foi categorizada de acordo com a participação da empresa nos níveis diferenciados de governança corporativa da BM\&FBovespa.

Com a finalidade de atender ao segundo objetivo específico, as empresas foram classificadas de acordo com os investimentos realizados em inovação, ademais, considerou-se a não utilização de investimentos em inovação. Assim, criaram-se as seguintes categorias de empresas: P - inovação via patentes; PD - inovação via P\&D; PPD - inovação via patentes e P\&D; e NI - não inovadoras.

Para identificar quais categorias de empresas apresentam semelhanças ou diferenças nos endividamentos, conforme os investimentos em inovação, efetuou-se o teste não paramétrico de Kruskal-Wallis, já que, após a realização do Teste de Kolmogorov-Smirnov, as variáveis do estudo não atenderam aos requisitos de normalidade em suas distribuições.

Como o Teste de Kruskal-Wallis não informa em quais investimentos as distribuições do endividamento se distinguem significativamente, procedeu-se à comparação múltipla das médias das ordens, recorrendo-se ao Teste LSD de Fisher (Maroco, 2007), o qual possibilita verificar o valor da média de cada endividamento referente a cada categoria de investimentos e, quanto maior for esse valor, conclui-se qual investimento em inovação leva a firma a registrar endividamento superior. Dessa forma, o procedimento realizado permite identificar em quais categorias as distribuições do endividamento são significativamente diferentes.

Para tanto, foram criadas as variáveis RECP, RELP e RETOT, que representam as ordens dessas variáveis e que, posteriormente, foram utilizadas para a comparação múltipla da média das ordens a partir da aplicação da Anova one-way, utilizando-se as variáveis criadas como variáveis dependentes e os investimentos em inovação como fatores.

Para atender ao objetivo geral e testar a hipótese de pesquisa, realizou-se a análise de regressão com utilização de dados em painel, para inferir acerca da correlação entre os construtos (Gujarati \& Porter, 2011). Como cada empresa está presente em todo o período analisado, os dados foram organizados em painéis balanceados, totalizando 360 observações.

Os investimentos em inovação e os endividamentos são testados separadamente, levando-se em consideração todo o período analisado, de acordo com os seguintes modelos econométricos:

$$
\begin{aligned}
& \text { IINOV } i_{i, t}=\alpha_{i}+61 E C P_{i, t}+62 I D A D E_{i, t}+63 E B / T D A+64 R O E_{i, t}+65 T_{A M} M_{i, t}+66 S E G_{-} L_{1 S T_{i, t}}+\varepsilon_{i, t}(1) \\
& \text { INNOV }_{i, t}=\alpha_{i}+61 E L P_{i, t}+62 I D A D E_{i, t}+63 E B I T D A+64 R O E_{i, t}+65 T A M_{i, t}+66 S E E_{-} \text {LST }_{i, t}+\varepsilon_{i, t}(2) \\
& \text { IINOV }{ }_{i, t}=\alpha_{i}+61 E T O_{i, t}+621 D A D E_{i, t}+63 E B I T D A+64 R O E_{i, t}+65 T_{A M} M_{i, t}+66 S E G_{-} \text {LISTi,t }_{i}+\varepsilon_{i, t} \text { (3) } \\
& P A T_{i, t}=\alpha_{i}+61 E C P_{i, t}+621 D A D E_{i, t}+63 E B I T D A+64 R O E_{i, t}+65 T A M_{i, t}+66 S E G_{-} L_{1 S T} T_{i, t}+\varepsilon_{i, t}(4) \\
& P A T_{i, t}=\alpha_{i}+61 E L P_{i, t}+62 I D A D E_{i, t}+63 E B I T D A+64 R O E_{i, t}+65 T A M_{i, t}+66 S E G_{-} L I S T_{i, t}+\varepsilon_{i, t}(5) \\
& P A T_{i, t}=\alpha_{i}+61 E T O_{i, t}+62 I D A D E_{i, t}+63 E B I T D A+64 R O E_{i, t}+65 T A M_{i, t}+66 S E G_{-} L_{1 S T_{i, t}}+\varepsilon_{i, t}(6)
\end{aligned}
$$

Em que:

IINOV = índice de inovação

PAT = investimento em inovação via patentes 


$$
\begin{aligned}
& E C P=\text { endividamento de curto prazo } \\
& E L P=\text { endividamento de longo prazo } \\
& E T O=\text { endividamento total } \\
& I D A D E=\text { idade } \\
& E B I T D A=\text { margem EBITDA } \\
& \text { ROE = rentabilidade } \\
& T A M=\text { tamanho }
\end{aligned}
$$
corporativa.

SEG_LIST é uma dummy referente à listagem nos níveis diferenciados de governança

Todas as variáveis foram analisadas levando-se em consideração a firma $i$ no ano $t$. $\varepsilon$ é o termo de erro.

Ressalta-se que para tal análise, inicialmente, são realizados o Teste LM (Lagrange Multiplier) de Breusch-Pagan e o Teste de Hausman, para identificar qual das três abordagens existentes pooled independent cross-sections (ou POLS - Pooled Ordinary Least Squares), efeitos fixos (fixed effects) e efeitos aleatórios (random effects) - representa melhor os dados nos modelos econométricos propostos (Gujarati \& Porter, 2011).

Cabe informar que foram realizados os testes de normalidade, heterocedasticidade e multicolinearidade de todos os modelos de regressão gerados e que na realização das análises foi aplicada a técnica robust, uma vez que esta corrige possíveis problemas estatísticos (Fávero, Belfiore, Silva, \& Chan, 2009).

\section{Apresentação e Análise dos Dados}

De início, nesta seção, é demonstrada a distribuição setorial das indústrias que compõem a amostra de estudo, segundo classificação da BM\&FBovespa. Tal distribuição é apresentada na Tabela 2.

Tabela 2:

Distribuição setorial das empresas

\begin{tabular}{|l|c|c|}
\hline Setores & Firmas & Proporção (\%) \\
\hline Consumo Cíclico & 32 & 26,7 \\
\hline Materiais Básicos & 30 & 25,0 \\
\hline Consumo não Cíclico & 27 & 22,5 \\
\hline Bens Industriais & 24 & 20,0 \\
\hline Construção e Transporte & 3 & 2,5 \\
\hline Petróleo, Gás e Biocombustíveis & 3 & 2,5 \\
\hline Tecnologia da Informação & 1 & 0,8 \\
\hline Total & $\mathbf{1 2 0}$ & $\mathbf{2 6 . 7}$ \\
\hline
\end{tabular}

Fonte: Elaborada pelos autores.

De acordo com a Tabela 2, nota-se que $26,7 \%$ das empresas da amostra pertencem ao setor Consumo Cíclico, o qual abrange indústrias automotivas, de eletrodomésticos, móveis, calçados e vestuário, em geral. Na sequência, com $25,0 \%$ de representatividade, estão as empresas do setor Materiais Básicos, que compreende as indústrias de embalagens, madeira e papel, mineração, química, siderurgia e metalurgia. Somente uma empresa da amostra $(0,8 \%)$, a Positivo Informática S.A., pertente ao setor Tecnologia da Informação.

Das informações contidas na Tabela 3, depreende-se que cresceram de maneira singela o número de observações referente ao registro de patentes e ao registro de patentes juntamente com gastos com $P \& D$, porém diminuíram as observações relacionadas a $P \& D$ individualmente. Em termos de observações, ano a ano, constata-se que nos anos de 2013 (54,2\%) e de 2015 (53,3\%) a maioria das firmas não realizou investimentos em inovação e que o ano 2014 foi o mais propício para a utilização dos investimentos em registros de patentes $(16,7 \%)$ e em P\&D $(14,2 \%)$ de forma separada.

Dentre os investimentos em inovação analisados, nota-se que, no período, os investimentos com P\&D foram os menos utilizados. Segundo a literatura, isso ocorre pelo fato de esse tipo de 
inovação consumir mais recursos e apresentar maior incerteza em relação aos retornos, justificandose o menor volume de recursos ali aplicados (Kim, 2015; March, 1991).

Para atender ao primeiro objetivo específico, delineia-se o perfil das empresas da amostra de acordo com a realização de investimentos em inovação, como mostra a Tabela 3.

Tabela 3:

Investimentos em inovação realizados pelas empresas no período

\begin{tabular}{|l|c|c|c|}
\hline \multirow{3}{*}{ Estratégia } & Ano & $\begin{array}{c}\text { Número de } \\
\text { observações }\end{array}$ & Proporção (\%) \\
\hline \multirow{3}{*}{ Patentes e P\&D } & 2013 & 24 & 20,0 \\
\cline { 2 - 4 } & 2014 & 24 & 20,0 \\
\cline { 2 - 4 } & 2015 & 26 & 21,7 \\
\hline \multirow{3}{*}{ Patentes } & 2013 & 15 & 12,5 \\
\cline { 2 - 4 } & 2014 & 20 & 16,7 \\
\cline { 2 - 4 } & 2015 & 16 & 13,3 \\
\hline \multirow{3}{*}{ P\&D } & 2013 & 16 & 13,3 \\
\cline { 2 - 4 } & 2014 & 17 & 14,2 \\
\cline { 2 - 4 } & 2015 & 14 & 54,7 \\
\cline { 2 - 4 } & 2013 & 65 & 49,2 \\
\cline { 2 - 4 } & 2014 & 59 & 53,3 \\
\hline
\end{tabular}

Fonte: Elaborada pelos autores.

De forma complementar, a Tabela 4 expõe os investimentos em inovação e os respectivos quantitativos de empresas da amostra, considerando o período analisado (2013-2015), complementando, assim, a Tabela 2.

Tabela 4:

Estratégias de inovação utilizadas pelas empresas no período analisado

\begin{tabular}{|l|c|c|}
\hline \multicolumn{1}{|c|}{ Estratégia } & Número de empresas & Proporção (\%) \\
\hline Patentes e P\&D & 31 & 25,8 \\
\hline Patentes & 30 & 25,0 \\
\hline P\&D & 12 & 10,0 \\
\hline Não inovadoras & 47 & 39,2 \\
\hline Total & 120 & 100,0 \\
\hline
\end{tabular}

Fonte: Elaborada pelos autores.

Na Tabela 4, nota-se a predominância de empresas que investem em inovação $(60,8 \%)$, enquanto as que não adotam nenhum dos investimentos em inovação considerados no estudo correspondem a aproximadamente $40 \%$ da amostra. É válido destacar que ao optar pela inovação, as empresas utilizam predominantemente patentes, numa proporção de $50,8 \%$, isso ao considerar o referido investimento individualmente e com $P \& D$ concomitantemente. Investimentos em inovação via $P \& D$ isoladamente são menos utilizados pelas empresas (10\%), o que corrobora os achados de Kayo e Famá (2004), segundo os quais as firmas brasileiras pouco investem nesse tipo de inovação, pelo fato de ser mais dispendioso e mais arriscado.

Os valores empregados em P\&D pelas empresas (total e médio), assim como sua proporção em relação às receitas líquidas de vendas são expostos na Tabela 5.

Tabela 5:

Dispêndios com $P \& D$ realizados pelas empresas

\begin{tabular}{|c|c|c|c|}
\hline Ano & Total $(\mathbf{R} \$)$ & Média $(\mathbf{R} \$)$ & $\begin{array}{c}\text { Proporção em relação às receitas } \\
(\%)\end{array}$ \\
\hline 2013 & $2.424 .589,00$ & $20.204,91$ & 0,15 \\
\hline 2014 & $2.938 .710,00$ & $24.489,25$ & 0,17 \\
\hline 2015 & $3.099 .218,00$ & $25.826,82$ & 0,17 \\
\hline Total & $\mathbf{8 . 4 6 2 . 5 1 7 , 0 0}$ & $\mathbf{7 0 . 5 2 0 , 9 8}$ & $\mathbf{0 , 1 6}$ \\
\hline
\end{tabular}

Fonte: Elaborada pelos autores.

De acordo com a Tabela 5, os dispêndios com P\&D cresceram ao longo do período analisado (2013-2015). Isso pode significar que as indústrias brasileiras vêm gradualmente aumentando o esforço para gerar inovação e se manterem competitivas, mesmo que o total dos gastos com P\&D corresponda a $0,17 \%$ das receitas de vendas. Esses resultados mostram consonância com os 
resultados de Kayo et al. (2006) e Santos et al. (2016), possivelmente porque, segundo Geiger e Makri (2006), esse tipo de investimento é dotado de maior incerteza quanto ao retorno do valor empregado. Assim, por conta do elevado risco, as empresas optam pela não utilização de recursos para custear tal investimento.

A Tabela 6 mostra a distribuição quantitativa anual (total e média) de patentes registradas, assim como apresenta a sua variação ano a ano.

Tabela 6:

Registro de patentes pelas empresas

\begin{tabular}{|c|c|c|c|}
\hline Ano & Quantidade & Média & Variação (\%) \\
\hline 2013 & 647 & 5 & --- \\
\hline 2014 & 1.036 & 9 & 60,1 \\
\hline 2015 & 885 & 7 & $-14,6$ \\
\hline Total & 2.568 & 21 & --- \\
\hline
\end{tabular}

Fonte: Elaborada pelos autores.

Na Tabela 6, nota-se que a quantidade de patentes cresceu 60,1\% em 2014, em comparação com o ano anterior e decresceu 14,6\% em 2015, em comparação com 2014. Os resultados demonstram que o ano 2014 foi aquele em que as firmas da amostra mais realizaram investimentos em registro de patentes, sendo considerado o mais propício para as indústrias brasileiras que objetivavam conseguir tal concessão. Além disso, levando-se em conta o período de análise, em média, foram registradas 21 patentes, quantidade considerada baixa, o que corrobora com os resultados do estudo de Kayo et al. (2006), segundo os quais os baixos gastos com P\&D nas firmas provocam impacto na quantidade de patentes registradas.

A Figura 2 demonstra a distribuição das indústrias da amostra, levando em conta seus respectivos segmentos industriais, segundo a classificação da BM\&FBovespa, as quais realizaram ou não os investimentos em inovação considerados no estudo.

Figura 2. Investimentos em inovação realizados pelas indústrias da amostra, por setor de atuação

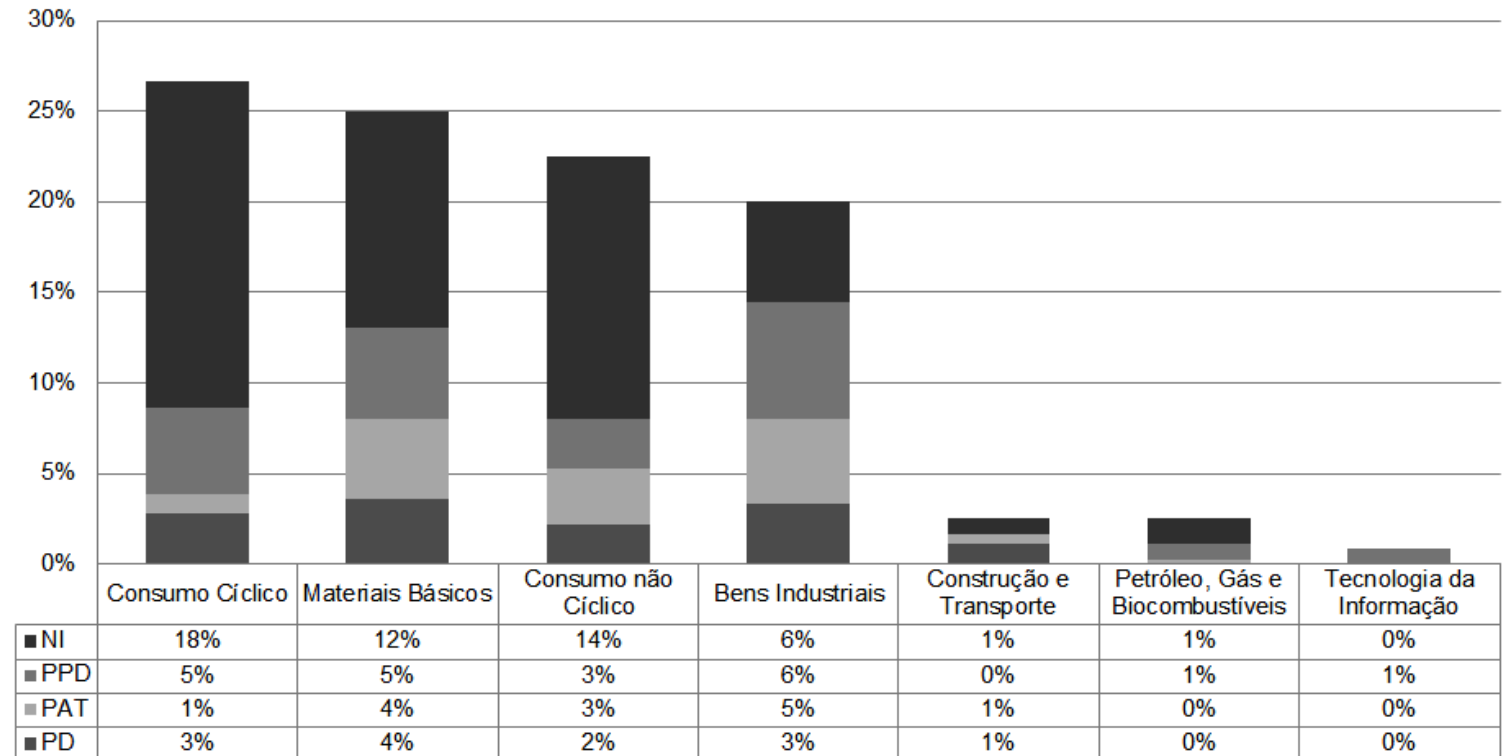

Legenda: PD: investimento em inovação via pesquisa e desenvolvimento (P\&D); PAT: investimento em inovação via patentes; PPD: investimento em inovação via patentes e P\&D; NI: não realizou investimentos em inovação.

Diante dos resultados da Figura 2, depreende-se que apesar de a maioria das empresas pertencer ao setor Consumo Cíclico, apenas $9 \%$ das empresas desse setor investiu em inovação. Além disso, destaca-se que $14 \%$ das firmas do setor Bens Industriais realizaram algum tipo de investimento em inovação, seja por meio de patentes, seja por meio de pesquisa e desenvolvimento, em separado ou de forma concomitante. Diante desse achado, o setor Bens Industriais é aquele que possui maior quantidade de firmas que investem conjuntamente nos tipos de inovação aqui estudados.

A Positivo Informática S.A., empresa representante do setor de Tecnologia da Informação, realiza investimentos em inovação via $P \& D$ e via registro de patentes. Por sua vez, nas indústrias 
Influência da estrutura de capital nos investimentos em inovação das indústrias listadas na BM\&FBOVESPA

pertencentes ao setor de Construção e Transportes, há utilização de investimentos em inovação de forma separada.

A Tabela 7 exibe um ranking com as cinco empresas mais inovadoras, considerando-se a quantidade de patentes no período de 2013 a 2015, e as correspondentes proporções das despesas com $P \& D$ em relação à receita líquida de vendas.

Tabela 7:

Ranking das empresas mais inovadoras

\begin{tabular}{|c|c|c|c|c|}
\hline $\begin{array}{l}\text { N. de } \\
\text { ordem }\end{array}$ & Empresa & $\begin{array}{c}\text { Quantidade } \\
\text { de } \\
\text { patentes }\end{array}$ & Empresa & $\begin{array}{c}\text { Proporção de P\&D } \\
\text { em relação às } \\
\text { receitas (\%) }\end{array}$ \\
\hline 10 & Whirlpool S.A. & 1.065 & Altus S. A. & 0,2129 \\
\hline 20 & Vale S. A. & 307 & $\begin{array}{c}\text { Positivo Informática } \mathrm{S} \text {. } \\
\mathrm{A} .\end{array}$ & 0,0696 \\
\hline 3으 & Grendene S. A. & 270 & Baumer S. A. & 0,0503 \\
\hline 40 & Petrobras S. A. & 226 & Lupatech S.A. & 0,0409 \\
\hline 5 음 & Metal Leve S. A. & 119 & Metal Leve S. A. & 0,0336 \\
\hline
\end{tabular}

Fonte: Elaborada pelos autores.

Diante do exposto na Tabela 7, a Whirlpool, do setor de eletrodomésticos, se destaca como a indústria mais inovadora, com 1.065 patentes registradas no período de 2013 a 2015. A Altus foi a empresa que mais investiu em P\&D, aplicando $R \$ 1.935 .318,00$, valor correspondente a 0,2129\% da receita de vendas. A Metal Leve é a única a figurar em ambos os rankings, ocupando a 5a posição em cada. Sendo assim, a Metal Leve, empresa brasileira de autopeças que atua na fabricação e comercialização de componentes de motores à combustão interna e filtros automotivos, é aquela que mais emprega recursos no tocante a inovação e, portanto, mostra-se como a indústria mais inovadora da amostra.

Em linhas gerais, nota-se que os investimentos em inovação nas indústrias brasileiras ainda são incipientes, quando comparados com as indústrias de países desenvolvidos. Esse fato pode estar atrelado aos baixos níveis de dispêndio com P\&D, haja vista que por conta do elevado risco, as empresas optam por investir menos em pesquisa e desenvolvimento (Santos et al., 2016), o que também influencia a quantidade de patentes registradas (Kayo et al., 2006).

Na sequência, analisam-se as associações entre as estratégias de inovação e as características das firmas (tamanho, idade, rentabilidade e segmento de listagem). Referidas associações são apresentadas via mapa perceptual, como mostra a Figura 3, e discutidas na sequência.

Da Figura 3, depreende-se que investimentos com registro de patentes estão associados com o baixo nível de rentabilidade (ROE) e com a idade de nível médio-baixo, ou seja, empresas com idade de constituição variando entre 30 e 55 anos.

Os investimentos em P\&D estão associados com idade e rentabilidade, ambas de nível médiobaixo, segmento de listagem Novo Mercado e tamanho médio-alto. Essas associações demonstram que a idade não é uma característica correlacionada com um investimento em inovação específico, pois, de acordo com o mapa perceptual, esse mesmo nível de idade se associa aos investimentos com registro de patentes, conforme comentado no parágrafo anterior. As firmas que pertencem ao Novo Mercado, por possuir mecanismos de governança corporativa além do exigido, são mais propensas a realizar investimentos em $P \& D$, os quais possuem custos mais elevados. Esse fato é explicado por Himmelberg, Hubbard e Palia (1999), segundo os quais o comprometimento da gestão, por meio de mecanismos de governança corporativa, é um fator importante, pois a realização de investimentos com P\&D pode culminar no desalinhamento de interesses na empresa.

No tocante ao tamanho, a Figura 3 demonstra que quanto maior é o porte, mais a firma investe em $P \& D$, ou seja, mais emprega recursos em investimentos em inovação com custos mais elevados (P\&D) bem como investe na aplicação de recursos diferentes e em conjunto, denotando, assim, uma relação positiva entre investimentos em inovação e tamanho da empresa.

As firmas não inovadoras associam-se às seguintes características: não são listadas em nenhum dos níveis diferenciados de governança corporativa da BM\&FBovespa; têm porte médiobaixo, confirmando a relação positiva entre os construtos, isto é, quanto menor o porte, menos inovadora é a firma; e registram alto nível de rentabilidade, denotando que quanto maior for a rentabilidade, menor a propensão a investir em inovação, assim como concluem Bartoloni (2013) e Miranda, Vasconcelos, Luca e Cabral (2015). 
Figura 3. Mapa perceptual estratégias de inovação x características das empresas

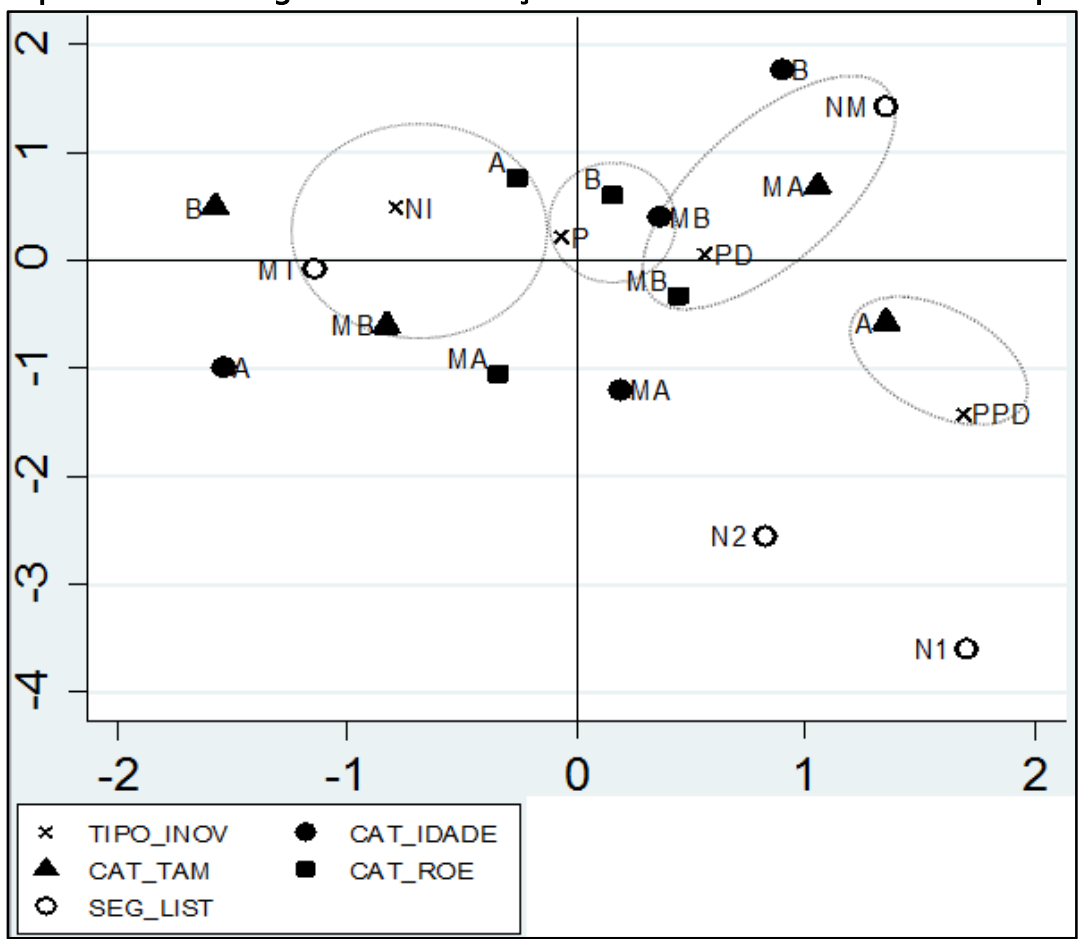

Legenda: TIPO_INOV - categorização dos investimentos em inovação: P: inovação via patentes; PD: inovação via P\&D; PPD: inovação via patentes e P\&D; NI: não realiza investimentos em inovação. CAT_IDADE - categorização da idade da firma: B: nível baixo; MB: nível médio-baixo; MA: nível médio-alto; $A$ : nível alto. CAT TAM categorização do tamanho da firma: B: nível baixo; MB: nível médio-baixo; MA: nível médio-alto; $A$ : nível alto. CAT ROE - categorização da rentabilidade da firma: B: nível baixo; MB: nível médio-baixo; MA: nível médio-alto; A: nível alto. SEG_LIST - categorização conforme participação nos níveis diferenciados de governança corporativa: N1, N2, NM; ou não: MT - mercado tradicional. Fonte: Elaborada pelos autores.

Para atender ao segundo objetivo específico, inicialmente procedeu-se à aplicação do Teste de Kolmogorov-Smirnov para se verificar a normalidade dos dados correspondentes às variáveis de estudo, conforme mostra a Tabela 8.

Tabela 8:

Teste de normalidade de Kolmogorov-Smirnov

\begin{tabular}{|l|c|c|}
\hline \multicolumn{1}{|c|}{ Variável } & Estatística & $p$-value \\
\hline IINOV & 0,389 & $0,000(* * *)$ \\
\hline PAT & 0,441 & $0,000(* * *)$ \\
\hline IDADE & 0,064 & $0,001(* * *)$ \\
\hline TAM & 0,074 & $0,000(* * *)$ \\
\hline ROE & 0,410 & $0,000(* * *)$ \\
\hline ECP & 0,393 & $0,000(* * *)$ \\
\hline ELP & 0,437 & $0,000(* * *)$ \\
\hline ETOT & 0,398 & $0,000(* * *)$ \\
\hline
\end{tabular}

Nota. ${ }^{(* *)}$ Significante ao nível de $1 \%$. Fonte: Elaborada pelos autores.

Verifica-se que todas as variáveis do estudo violaram a hipótese de distribuição normal, já que todas apresentam $p$-value inferior a 0,05. Assim, o Teste de Kruskal-Wallis é o recomendado para identificar semelhanças e diferenças na configuração da estrutura de capital.

Dessa maneira, verifica-se a existência de diferenças na configuração da estrutura de capital, dada pelas variáveis de endividamento, conforme os investimentos em inovação via patentes (P), $P \& D(P D)$, patentes e P\&D (PPD) e não inovadoras (NInov). A Tabela 9 mostra os resultados desse teste.

De acordo com a Tabela 9, as variáveis representativas da estrutura de capital se mostraram significantes ( $p$-value $=0,0001)$, o que leva à rejeição da hipótese nula de igualdade na distribuição de valores, permitindo concluir que há diferenças nas distribuições do endividamento de acordo com os investimentos em inovação. Entretanto, como o Teste de Kruskal-Wallis não informa em qual ou em quais investimentos as distribuições do endividamento se distinguem significativamente, 
procedeu-se à comparação múltipla das médias das ordens, sendo esse procedimento adequado apenas após ter sido rejeitada a hipótese nula no Teste de Kruskal-Wallis (Maroco, 2007).

Tabela 9:

Teste de Kruskal-Wallis: Endividamento e investimentos em inovação

\begin{tabular}{|l|c|c|}
\hline \multicolumn{1}{|c|}{ Variável } & Qui-Quadrado & $p$-value \\
\hline ECP & 24,542 & $0,0000\left(^{* * *}\right)$ \\
\hline ELP & 8,992 & $0,0290\left(^{* *}\right)$ \\
\hline ETOT & 20,534 & $0,0000\left(^{* * *}\right)$ \\
\hline
\end{tabular}

Legenda: ECP: Endividamento de curto prazo; ELP: Endividamento de longo prazo; ETOT: Endividamento total. Nota. ${ }^{(* *)}$ Significante ao nível de $1 \% .{ }^{(* *)}$ Significante ao nível de 5\%. Fonte: Elaborada pelos autores.

Tabela 10:

Comparação múltipla das médias (Teste LSD de Fisher) - investimentos em inovação PAINEL A - Endividamento de Curto Prazo (ECP)

\begin{tabular}{|c|c|c|c|}
\hline \multicolumn{4}{|c|}{ PAINEL A - Endividamento de Curto Prazo (ECP) } \\
\hline Investimentos (I) & Métrica (J) & $\begin{array}{c}\text { Diferença média (I- } \\
\mathrm{J})\end{array}$ & $p$-value \\
\hline \multirow[t]{3}{*}{ (1) } & PAT & $-34,9833$ & 0,087 \\
\hline & PPD & $-23,7737$ & 0,207 \\
\hline & Ninov & $-71,7021$ & $0,000\left(^{* *}\right)$ \\
\hline \multirow{3}{*}{ PAT } & PD & 34,9833 & 0,087 \\
\hline & PPD & 11,2095 & 0,542 \\
\hline & Ninov & $-36,7188$ & $0,022(* *)$ \\
\hline \multirow{3}{*}{ PPD } & PD & 23,7737 & 0,207 \\
\hline & PAT & $-11,2095$ & 0,542 \\
\hline & Ninov & $-47,9284$ & $0,001\left(^{* *}\right)$ \\
\hline \multirow{3}{*}{ NInov } & PD & 71,7021 & $0,000\left(^{* *}\right)$ \\
\hline & PAT & 36,7188 & $0,022\left(^{* *}\right)$ \\
\hline & PPD & 47,9284 & $0,001(* *)$ \\
\hline \multicolumn{4}{|c|}{ PAINEL B - Endividamento de Longo Prazo (ELP) } \\
\hline Investimentos (I) & Métrica (J) & Diferença média (I-J) & p-value \\
\hline \multirow[t]{3}{*}{ (1) } & PAT & $-49,8777$ & $0,017(* *)$ \\
\hline & PPD & 2,3355 & 0,903 \\
\hline & Ninov & $-19,3510$ & 0,251 \\
\hline \multirow{3}{*}{ PAT } & $\mathrm{PD}$ & 49,8777 & $0,017(* *)$ \\
\hline & PPD & 52,2133 & $0,006\left(^{* *}\right)$ \\
\hline & Ninov & 30,5267 & 0,062 \\
\hline \multirow{3}{*}{ PPD } & PD & $-2,3355$ & 0,903 \\
\hline & PAT & $-52,2133$ & $0,006\left(^{* *}\right)$ \\
\hline & Ninov & $-21,6866$ & 0,127 \\
\hline \multirow{3}{*}{ NInov } & PD & 19,3510 & 0,251 \\
\hline & PAT & $-30,5267$ & 0,062 \\
\hline & PPD & 21,6866 & 0,127 \\
\hline \multicolumn{4}{|c|}{ PAINEL C - Endividamento Total (ETOT) } \\
\hline Investimentos (I) & Métrica (J) & Diferença média (I-J) & $p$-value \\
\hline \multirow[t]{3}{*}{ 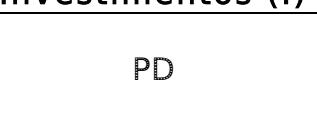 } & PAT & $-54,8231$ & $0,008(* *)$ \\
\hline & PPD & $-14,6771$ & 0,439 \\
\hline & Ninov & $-62,1595$ & $0,000\left(^{* *}\right)$ \\
\hline \multirow{3}{*}{ PAT } & PD & 54,8231 & $0,008\left(^{* *}\right)$ \\
\hline & PPD & 40,1459 & $0,030\left(^{* *}\right)$ \\
\hline & Ninov & $-7,3364$ & 0,647 \\
\hline \multirow{3}{*}{ PPD } & $\mathrm{PD}$ & 14,6771 & 0,439 \\
\hline & PAT & $-40,1459$ & $0,030\left(^{* *}\right)$ \\
\hline & Ninov & $-47,4824$ & $0,001\left(^{* *}\right)$ \\
\hline \multirow{3}{*}{ Ninov } & PD & 62,1595 & $0,000\left(^{* *}\right)$ \\
\hline & PAT & 7,3364 & 0,647 \\
\hline & PPD & 47,4824 & $0,001\left(^{* *}\right)$ \\
\hline
\end{tabular}

Legenda: PAT: patentes; PD: pesquisa e desenvolvimento; PPD: patentes e pesquisa e desenvolvimento; NInov: não inovadoras. Nota. ${ }^{(*)}$ Significante ao nível de $5 \%$. Fonte: Elaborada pelos autores.

Para tanto, recorre-se ao Teste LSD de Fisher, a partir da utilização das variáveis RECP, RELP e RETOT, as quais foram utilizadas para a comparação múltipla da média das ordens a partir da aplicação da Anova one-way. Os investimentos em inovação foram considerados nesse teste como 
fatores, em conformidade com a utilização de recursos para custear investimentos em inovação. Ressalta-se que para manter um padrão na análise dos resultados oriundos do Teste LSD de Fisher, somente considerou-se 0,05 como nível de significância estatística. Os resultados são apresentados na Tabela 10.

Das informações contidas na Tabela 10, no que tange ao Endividamento de Curto Prazo Painel A, nota-se que ao realizar investimentos em um ou mais tipos de inovação considerados nesse estudo, as firmas apresentam uma distribuição de endividamento diferente quando comparadas com aquelas que não realizam investimentos em inovação, ou seja, o endividamento em firmas inovadoras é diferente daquele verificado nas não inovadoras, assim como em Chen, Hsu e Huang (2010), Kayo e Famá (2004) e Li e Simerly (2002).

Já no tocante ao Endividamento de Longo Prazo - Painel B, percebe-se que somente o investimento em diferentes inovações provoca modificação no endividamento das firmas da amostra. Assim, ao investir em inovação via registro de patentes, o endividamento de longo prazo difere daquele verificado nas empresas que investem em inovação via $P \& D$, bem como há diferença quando comparadas empresas que adotam concomitantemente os investimentos em inovação via registro de patentes e via $P \& D$.

No que tange ao Endividamento Total - Painel C, percebe-se que as firmas que investem em inovação via $P \& D$ e as que investem concomitantemente em patentes e em $P \& D$ possuem endividamento total diferente daquele existente tanto nas firmas que investem em inovação via patentes, quanto nas firmas que não adotam a inovação em seu contexto.

Dessa forma, ao se considerar os endividamentos de longo prazo e total, percebe-se que até mesmo investimentos diferentes em inovação fazem com que a estrutura de capital seja modificada. Essas evidências corroboram a afirmação de O'Brien (2003) de que a escassez de recursos próprios leva a empresa a analisar qual estrutura de capital atende às suas necessidades de inovação, já que a estrutura de capital pode ser considerada fonte de criação de valor para a firma.

Diante do apresentado, conforme a média de endividamento e a média dos rankings do Teste de Kruskal-Wallis para cada grupo de análise, pode-se inferir sobre o nível de endividamento segundo a realização de investimentos em inovação. Esses resultados estão contidos na Tabela 11.

Tabela 11:

Média do endividamento conforme investimentos em inovação

PAINEL A - Endividamento de Curto Prazo (ECP)

\begin{tabular}{|c|c|c|c|}
\hline Investimentos & $\begin{array}{c}\text { № de } \\
\text { observações }\end{array}$ & $\begin{array}{c}\text { Média do } \\
\text { Endividamento }\end{array}$ & $\begin{array}{c}\text { Média dos } \\
\text { Rankings }\end{array}$ \\
\hline PD & 47 & 0,2820 & 133,2127 \\
\hline PAT & 51 & 0,3277 & 168,1960 \\
\hline PPD & 74 & 0,3074 & 156,9864 \\
\hline Ninov & 188 & 0,9236 & 204,9148 \\
\hline \multicolumn{4}{|c|}{ PAINEL B - Endividamento de Longo Prazo (ELP) } \\
\hline Investimentos & $\begin{array}{c}\text { № de } \\
\text { observações }\end{array}$ & $\begin{array}{c}\text { Média do } \\
\text { Endividamento }\end{array}$ & $\begin{array}{c}\text { Média dos } \\
\text { Rankings }\end{array}$ \\
\hline $\mathrm{PD}$ & 47 & 0,3314 & 163,8085 \\
\hline PAT & 51 & 0,5002 & 213,6862 \\
\hline PPD & 74 & 0,2871 & 161,4729 \\
\hline Ninov & 188 & 1,4152 & 183,1595 \\
\hline \multicolumn{4}{|c|}{ PAINEL C - Endividamento Total (ETOT) } \\
\hline Investimentos & $\begin{array}{c}\text { № de } \\
\text { observações }\end{array}$ & $\begin{array}{c}\text { Média do } \\
\text { Endividamento }\end{array}$ & $\begin{array}{c}\text { Média dos } \\
\text { Rankings }\end{array}$ \\
\hline $\mathrm{PD}$ & 47 & 0,6134 & 137,2553 \\
\hline PAT & 51 & 0,8279 & 192,0784 \\
\hline PPD & 74 & 0,5946 & 151,9324 \\
\hline Ninov & 188 & 2,3389 & 199,4148 \\
\hline
\end{tabular}

Legenda: PD: P\&D; PAT: patentes; PPD: patentes e P\&D; NInov: não inovadoras. Fonte: Elaborada pelos autores.

Na Tabela 11, constata-se que, em média, os endividamentos das firmas não inovadoras são superiores aos das empresas inovadoras, o que denota a existência de uma correlação inversa entre investimentos em inovação e endividamento, como em Chen et al. (2010), Kayo e Famá (2004) e Li e Simerly (2002).

Já as firmas que investem em inovação via patentes contabilizam endividamentos de curto prazo, longo prazo e total superiores aos das firmas que investem em inovação via P\&D. Assim, os 
resultados sugerem que os investimentos em inovação via $P \& D$ reduzem o endividamento das firmas.

Assim, como em Kayo e Famá (2004) e Li e Simerly (2002), pode-se afirmar que quanto mais baixo é o endividamento, mais propensa a firma é a desenvolver e utilizar capacidades inovadoras. Outro ponto a ser destacado é que como níveis inferiores de endividamento estão relacionados com o investimento em alguma estratégia de inovação, deduz-se que as indústrias utilizam outras fontes de recursos, tais como fundos internos, ao invés de dívidas para financiar a inovação, assim como os resultados apontados por Bartoloni (2013) em estudo sobre as firmas italianas.

Para atingir o objetivo geral, inicialmente aplicaram-se o Teste de Breusch-Pagan e o Teste de Hausman, os quais indicaram que a abordagem de efeitos aleatórios (random effects) é a mais indicada para os modelos econométricos propostos.

A Tabela 12 apresenta a regressão linear múltipla com dados em painel para a relação entre investimentos em inovação via P\&D e os endividamentos.

Tabela 12:

\begin{tabular}{|c|c|c|c|c|c|c|}
\hline $\begin{array}{l}\text { Modelos } \\
\text { (IINOV) }\end{array}$ & \multicolumn{2}{|c|}{ Equação 1} & \multicolumn{2}{|c|}{ Equação 2} & \multicolumn{2}{|c|}{ Equação 3} \\
\hline Variável & Coef. & Sig & Coef. & Sig & Coef. & Sig \\
\hline ECP & $-0,0002$ & 0.2830 & ----- & ---- & ----- & ----- \\
\hline ELP & ----- & ----- & $-0,0001$ & 0,1220 & ----- & ----- \\
\hline ETOT & ----- & ----- & ----- & ----- & $-0,0001$ & 0,1170 \\
\hline EBITDA & 0,0000 & $0,0360\left(^{(* *)}\right.$ & 0,0000 & 0,0350 (**) & 0,0000 & 0,0350 (**) $^{*}$ \\
\hline IDADE & $-0,0001$ & 0,3700 & $-0,0001$ & 0,3680 & $-0,0001$ & 0,3700 \\
\hline TAM & $-0,0019$ & 0,0500 (**) & $-0,0019$ & $0,0490{ }^{(* *)}$ & $-0,0020$ & 0,0480 (**) \\
\hline ROE & 0,0000 & 0,4470 & 0,0000 & 0,4570 & 0,0000 & 0,4570 \\
\hline GOV & 0,0058 & 0,1790 & 0,0058 & 0,1770 & 0,0058 & 0,1780 \\
\hline Cons & 0,0356 & $0,0800\left(^{*}\right)$ & 0,0359 & $0,0780(*)$ & 0,0364 & $0,0780\left(^{*}\right)$ \\
\hline Wald & \multicolumn{2}{|c|}{11,49} & \multicolumn{2}{|c|}{13,51} & \multicolumn{2}{|c|}{14,42} \\
\hline$p$-value & \multicolumn{2}{|c|}{$0,0744(*)$} & \multicolumn{2}{|c|}{$0,0356(* *)$} & \multicolumn{2}{|c|}{$0,0253(* *)$} \\
\hline R2 & \multicolumn{2}{|c|}{0,0306} & \multicolumn{2}{|c|}{0,0314} & \multicolumn{2}{|c|}{0,0322} \\
\hline
\end{tabular}

Nota. ${ }^{(*)}$ e $\left(^{*}\right)$ significância estatística dos coeficientes em $5 \%$ e $10 \%$, respectivamente. Fonte: Elaborada pelos autores.

De acordo com a Tabela 12, apesar do poder explicativo dos modelos ser igual a $3 \%$, em média, infere-se que nenhuma das proxies de endividamento tem relação com os investimentos em inovação via P\&D, assim como em O'Brien (2003), contrastando com o estudo de Abreu et al. (2015).

Destaca-se que a variável EBITDA influencia, considerando nível de significância de 5\%, os investimentos em inovação via pesquisa e desenvolvimento, contribuindo para o aumento destes. Assim, a capacidade de geração de fluxo de caixa nas indústrias analisadas determina o investimento em P\&D. Tal fato vai ao encontro da Teoria Pecking Order, pois, baseado nos resultados, as firmas da amostra estão se utilizando de recursos próprios para investir em inovação. Esse achado também é significativo sob o ponto de vista da Teoria da Agência, pois, nesse caso, ao se deparar com um maior volume de fluxo de caixa livre, maior é a tendência do gestor em investir recursos excedentes em projetos que não remunerem o capital investido, o que pode culminar no futuro em um conflito de agência (Kayo \& Fama, 2004).

Por sua vez, a variável tamanho influencia negativamente os investimentos em $P \& D$, o que diverge dos resultados de Acs e Isberg (1991) e Lai et al. (2015).

Diante disto, segundo a literatura, isso ocorre pelo fato desse tipo de inovação consumir mais recursos e apresentar maior incerteza em relação aos retornos (Kim, 2015; March, 1991). Assim, é importante destacar que, como os investimentos em P\&D são mais arriscados, o financiamento externo acaba sendo mais dispendioso, o que leva às empresas a recorrerem ao autofinanciamento.

A Tabela 13 apresenta a regressão linear múltipla com dados em painel para a relação entre investimento em inovação via patentes e os endividamentos.

Na Tabela 13, cabe destacar que os modelos analisados têm uma capacidade explicativa de $17 \%$, em média, permitindo inferir que o endividamento de longo prazo e o endividamento total têm relação com a inovação via registro de patentes, sendo que há influência positiva daquelas sobre 
esta, contrastando com os achados de Abreu et al. (2015). Esses resultados evidenciam que as empresas com endividamento de longo prazo e endividamento total são as que registram maior número de patentes, ou seja, ambos os grupos contribuem para a utilização de investimentos em inovação através do registro de patentes.

Tabela 13:

Análise de regressão linear múltipla entre investimentos em inovação via patentes e os endividamentos

\begin{tabular}{|c|c|c|c|c|c|c|}
\hline $\begin{array}{c}\text { Modelos } \\
\text { (PAT) }\end{array}$ & \multicolumn{2}{|c|}{ Equação 4} & \multicolumn{2}{|c|}{ Equação 5} & \multicolumn{2}{|c|}{ Equação 6} \\
\hline Variável & Coef. & Sig & Coef. & Sig & Coef. & Sig \\
\hline ECP & 0,0150 & 0,171 & ---- & --- & ---- & --- \\
\hline ELP & ---- & ---- & 0,0072 & $0,022 * *$ & ---- & ---- \\
\hline ETOT & ---- & $\begin{array}{l}--- \\
--\end{array}$ & --- & --- & 0,0087 & $0,032(* *)$ \\
\hline EBITDA & 0,0000 & $0,001(* * *)$ & 0,0000 & 0,001 (***) & 0,0000 & $0,001(* * *)$ \\
\hline IDADE & 0,0040 & 0,121 & 0,0041 & 0,117 & 0,0040 & 0,121 \\
\hline TAM & 0,2032 & $0,001(* * *)$ & 0,2036 & $0,001(* * *)$ & 0,2065 & 0,001 (***) \\
\hline ROE & 0,0003 & 0,895 & 0,0002 & 0,905 & 0,0003 & 0,898 \\
\hline SEG_LIST & 0,2126 & 0,363 & 0,2112 & 0,367 & 0,2120 & 0,366 \\
\hline Cons & $-2,7471$ & $0,001(* * *)$ & $-2,7516$ & 0,001 (***) $^{2}$ & $-2,7981$ & 0,001 (***) $^{2}$ \\
\hline Wald & \multicolumn{2}{|c|}{22,21} & \multicolumn{2}{|c|}{26,71} & \multicolumn{2}{|c|}{24,33} \\
\hline$p$-value & \multicolumn{2}{|c|}{0,0011 (***) } & \multicolumn{2}{|c|}{$0,0002(* * *)$} & \multicolumn{2}{|c|}{$0,0005(* * *)$} \\
\hline R2 & \multicolumn{2}{|c|}{0,1710} & \multicolumn{2}{|c|}{0,1711} & \multicolumn{2}{|c|}{0,1725} \\
\hline
\end{tabular}

Nota. $\left(^{* * *}\right)$ e (**) Significância estatística dos coeficientes em $1 \%$ e $5 \%$, respectivamente. Fonte: Elaborada pelos autores.

Outro achado importante é que essas empresas podem estar utilizando-se de recursos internos de forma preliminar, haja vista a influência da margem EBITDA sobre as métricas de inovação consideradas. Diante do exposto, é possível dizer que esses resultados estão de acordo com o preconizado pela Teoria Peckin Order, pois se presume a existência de uma hierarquia no tocante às fontes de financiamento. Em primeiro lugar, por recursos internos (fluxo de caixa EBITDA) e em seguida por recursos de terceiros (endividamento) (Alves et al., 2015; Florackis, Kanas, \& Kostakis, 2015; Myers \& Majluf, 1984; Nhung \& Okuda, 2015). Também, pela Teoria da Agência, porque com o endividamento, além da possível redução dos custos de agência, diminui-se o fluxo de caixa livre, o que reduz os investimentos discricionários dos gestores (Frank \& Goyal, 2003; Jensen \& Meckling, 1976; Kayo \& Fama, 2004; Medeiros \& Daher, 2008).

É válido destacar que para investir em inovação, as firmas utilizaram recursos de terceiros, já que os recursos empregados com inovação são de maior vulto, haja vista, principalmente, a influência do endividamento de longo prazo (Crisóstomo, 2009).

A variável tamanho apresentou uma relação positiva com os investimentos em inovação via patentes. Esse resultado indica que as empresas maiores patenteiam mais, indo ao encontro dos resultados sinalizados por Acs e Isberg (1991) e por Lai et al. (2015).

Destarte, a hipótese de estudo, segundo a qual a estrutura de capital influencia os investimentos em inovação nas indústrias listadas na BM\&FBovespa, é rejeitada, pois somente ao considerar os endividamentos de longo prazo e total, aliados ao investimento em inovação via patentes, é que se vê tal influência, demonstrando-se, desse modo, uma relação importante entre os construtos, mas que requer estudos mais aprofundados.

\section{Conclusões e Recomendações}

Analisou-se a influência da estrutura de capital nos investimentos em inovação das indústrias listadas na BM\&FBovespa. Para tanto, os endividamentos de curto prazo, de longo prazo e total foram utilizados como proxies para a estrutura de capital, enquanto os investimentos em inovação foram mensurados de acordo com o dispêndio com P\&D e a quantidade de patentes registradas.

Verificou-se que $60,8 \%$ das firmas investem em inovação, o que demonstra um perfil de estratégia das empresas brasileiras pesquisadas. Nas indústrias que investem somente em pesquisa e desenvolvimento, percebeu-se que esse dispêndio cresceu ao longo do período analisado, mostrando que as empresas vêm gradualmente aumentando a utilização desses investimentos como forma de inovar e se manter competitivas, mesmo que esses investimentos correspondam a um baixo percentual da receita líquida de vendas. Esse resultado demonstra que como os 
investimentos em inovação via $P \& D$ são dotados de maior incerteza quanto ao retorno do investimento, por conta do seu elevado risco, as empresas têm a opção de investir menos recursos neste tipo de inovação. Observou-se que o ano de 2014 foi propício para as indústrias brasileiras que objetivavam realizar registro de patentes, assinalando aumento de $60,1 \%$ em relação ao ano anterior. Entretanto, os baixos investimentos com $P \& D$ acarretam impacto negativo na quantidade de patentes registradas.

Considerando as firmas analisadas, observa-se que a Metal Leve, indústria de autopeças, é aquela que mais emprega recursos no tocante à inovação, ou seja, é a firma mais inovadora da amostra, pois está presente em ambos os rankings elaborados para classificar as empresas quanto aos investimentos em inovação. Por meio da Análise de Correspondência Múltipla, inferiu-se que as empresas com idade de constituição variando entre 30 a 55 anos investem em inovação via registro de patentes com a finalidade de melhorar a rentabilidade.

Por meio do Teste de Kruskal-Wallis, observou-se que há diferenças nas distribuições do endividamento de acordo com os investimentos em inovação das empresas. De forma complementar, aplicou-se o Teste LSD de Fisher, o qual permitiu concluir que, ao se considerar o endividamento de curto prazo, verificou-se que a adoção de um ou ambos investimentos em inovação aqui considerados, faz com que o endividamento seja diferente daquele existente nas firmas que não investem em inovação. No tocante aos endividamentos de longo prazo e total, percebeu-se que até mesmo investimentos em inovação diferentes fazem com que os endividamentos se diferenciem. Em média, os endividamentos (curto prazo, longo prazo e total) das firmas não inovadoras são superiores aos das empresas inovadoras, o que denota a existência de uma relação inversa entre investimentos em inovação e endividamento.

Através da regressão linear múltipla com dados em painel foi possível concluir que somente os endividamentos de longo prazo e total influenciam positivamente os investimentos em inovação via registro de patentes. Esse resultado leva à rejeição da hipótese de estudo, pois essa influência é encontrada somente ao se considerar os endividamentos de longo prazo e total, analisados em relação aos investimentos em inovação por registro de patentes.

Outro achado importante é que essas empresas podem estar utilizando recursos internos preliminarmente, mesmo que de forma reduzida, haja vista a influência da margem EBITDA sobre ambas as métricas de inovação consideradas nesse estudo.

Em linhas gerais, seguindo as recomendações da literatura, é possível dizer que esses resultados estão em harmonia com a Teoria Pecking Order, pois se presume a existência de uma hierarquia no tocante as fontes de financiamento, primeiro por recursos internos (fluxo de caixa EBITDA) e em seguida por recursos de terceiros (endividamento), e também com a Teoria da Agência, porque através do endividamento é possível reduzir os custos de agência e diminuir o fluxo de caixa livre, o que reduz os investimentos discricionários dos agentes.

Assim, as evidências sinalizadas nessa pesquisa sugerem que as empresas utilizem recursos internos, como o fluxo de caixa, para investir em inovação via P\&D e, de forma adicional, constatouse que as dívidas de longo prazo contribuem para as empresas utilizarem a inovação via registro de patentes, ou seja, valer-se de recursos de terceiros para custear esta inovação.

Como contribuição, destaca-se o fato de o estudo ajudar a ampliar a incipiente literatura nacional, relacionando os construtos estrutura de capital e inovação, bem como subsidiar os gestores a decidir sobre a maneira de combinar as fontes de financiamento, o que constitui decisão de extrema importância no contexto das empresas.

Apesar do rigor metodológico adotado, os resultados foram obtidos a partir de uma amostra intencional (indústrias listadas na BM\&FBovespa), não se podendo, dessa forma, fazer generalizações. Outra importante limitação do estudo é que as indústrias da amostra estão distribuídas em segmentos industriais com diferentes padrões tecnológicos (Pavitt, 1982). Logo, sugere-se a realização de novas pesquisas com ampliação da amostra, bem como a inserção de outras variáveis para mensuração da inovação. Recomenda-se, ainda, que sejam realizadas pesquisas com o intuito de comparar o perfil da inovação e da configuração da estrutura de capital das firmas brasileiras com os das firmas de outros países em desenvolvimento ou de países desenvolvidos. 


\section{Notas}

1. Cumpre salientar que os autores agradecem a leitura criteriosa dos pareceristas da RECADM, cujas recomendações foram, não apenas acatadas, mas fonte de reflexão e inspiração para reformulações mais substantivas do artigo.

2. Os autores agradecem o apoio do CNPq, que financiou as pesquisas nas quais o texto se baseia.

\section{Referências}

Abreu, E. S., Bruni, A. L., Gomes, S. M. S., \& Paixão, R. B. (2015). Relações entre inovação tecnológica e estrutura de capital: um estudo de empresas brasileiras de capital aberto. Revista de Administração e Inovação, 12(2), 326-350.

Acs, Z. J., \& Isberg, S. C. (1991). Innovation, firm size and corporate finance: an initial inquiry. Economics Letters, 35(3), 323-326.

Allred, B. B., \& Park, W. G. (2007). Patent rights and innovative activity: evidence from national and firm-level data. Journal of International Business Studies, 38(6), 878-900.

Alves, P., Couto, E. B., \& Francisco, P. M. (2015). Board of directors' composition and capital structure. Research in International Business and Finance, 35(1), 1-32.

Alti, A. (2006). How persistent is the impact of market timing on capital structure?. The fournal of Finance, 61(4), 1681-1710.

Arosa, C. M. V., Richie, N., \& Schuhmann, P. W. (2014). The impact of culture on market timing in capital structure choices. Research in International Business and Finance, 31(1), 178-192.

Assaf Neto, A. (2014). Finanças corporativas e valor. (7a ed). São Paulo: Atlas.

Bach, L. (2013). Are small businesses worthy of financial aid? Evidence from a French targeted credit program. Review of Finance, 18(1), 877-919.

Baker, M., \& Wurgler, J. (2002). Market timing and capital structure. The fournal of Finance, 57(1), 132.

Bartoloni, E. (2013). Capital structure and innovation: causality and determinants. Empirica, 40(1), 111-151.

Baumann, J., \& Kritikos, A. S. (2016). The link between R\&D, innovation and productivity: are micro firms different?. Research Policy, 45(6), 1263-1274.

Blass, A. A., \& Yosha, O. (2003). Financing R\&D in mature companies: an empirical analysis. Economics of Innovation and New Technology, 12(5), 425-447.

Boehe, D. M., Larentis, F., Toni, D. De, \& Mattia, A. Á. (2011). Papel das relações interorganizacionais e da capacidade de inovação na propensão para exportar. Revista Eletrônica de Administração, 17(1), 87-117.

Bolton, P., Chen, H., \& Wang, N. (2013). Market timing, investment, and risk management. Journal of Financial Economics, 109(1), 40-62.

Brito, E. P. Z., Brito, L. A. L., \& Morganti, F. (2009). Inovação e desempenho empresarial: lucro ou crescimento?. RAE-Eletrônica, 8(1).

Brito, G. A. S., Corrar, L. J., \& Batistella, F. D. (2007). Fatores determinantes da estrutura de capital das maiores empresas que atuam no Brasil. Revista Contabilidade \& Finanças, 18(43), 9-19.

Burlamaqui, L., \& Proença, A. (2003). Inovação, recursos e comprometimento: em direção a uma teoria estratégica da firma. Revista Brasileira de Inovação, 2(1), 79-110.

Camilo, S. P., Xavier, W. G., Bandeira-de-Mello, R., \& Marcon, R. (2010). A estrutura de capital como recurso e o efeito no desempenho das firmas. Revista Ibero Americana de Estratégia, 9(1), 102-126.

Campara, J. P., Vieira, K. M., \& Ceretta, P. S. (2016). Entendendo a atitude ao endividamento: fatores comportamentais e variáveis socioeconômicas o determinam? Revista Eletrônica de Ciência Administrativa, 15(1), 5-24.

Campos, A. L. S., \& Nakamura, W. T. (2013). Folga financeira avaliada como endividamento relativo e estrutura de capital. Revista de Finanças Aplicadas, 1, 1-19. 
Canto, J. G. Del, \& Gonzalez, I. S. (1999). A resource-based analysis of the factors determining a firm's R\&D activities. Research Policy, 28(8), 891-905.

Chen, H., Hsu, W., \& Huang, Y. (2010). Top management team characteristics, R\&D investment and capital structure in the IT industry. Small Business Economics, 35(3), 319-333.

Correa, C. A., Basso, L. F. C., \& Nakamura, W. T. (2013). A estrutura de capital das maiores empresas brasileiras: análise empírica das teorias de pecking order e trade-off, usando panel data. Revista de Administração Mackenzie, 14(4), 106-133.

Crisóstomo, V. L. (2009). Ativos intangíveis: estudo comparativo dos critérios de reconhecimento, mensuração e evidenciação adotados no Brasil e em outros países. Contabilidade, Gestão e Governança, 1(1), 50-68.

Crisóstomo, V. L., López-Iturriaga, F. J., \& Vallelado, E. (2011). Financial constraints for innovation in Brazil. Latin American Business Review, 12(3), 165-185.

Christensen, P. O., Flor, C. R., Lando, D., \& Miltersen, K. R. (2014). Dynamic capital structure with callable debt and debt renegotiations. Journal of Corporate Finance, 29(1), 644-661.

Crossan, M. M., \& Apaydin, M. (2010). A multi-dimensional framework of organizational innovation: a systematic review of the literature. Journal of Management Studies, 47(6), 1154-1191.

Dai, L., Maksimov, V., Gilbert, B. A., \& Fernhaber, S. A. (2014). Entrepreneurial orientation and international scope: the differential roles of innovativeness, proactiveness, and risk-taking. Journal of Business Venturing, 29(4), 511-524.

Dalziel, T., Gentry, R. J., \& Bowerman, M. (2011). An integrated agency-resource dependence view of the influence of directors' human and relational capital on firms' R\&D spending. Journal of Management Studies, 48(6), 1217-1242.

Fávero, L. P., Belfiore, P., Silva, F. L., Chan, B. L. (2009). Análise de dados: modelagem multivariada para tomada de decisões. (4. ed.). Rio de Janeiro: Elsevier.

Fonseca, C. V. C., Silveira, R. L. F. da, \& Hiratuka, C. (2016). A relação entre a governança corporativa e a estrutura de capital das empresas brasileiras no período 2000-2013. Enfoque, 35(2), 35-52.

Florackis, C., Kanas, A., \& Kostakis, A. I. (2015). Dividend policy, managerial ownership and debt financing: A non-parametric perspective. European Journal of Operational Research, 241(3), 783-795.

Frank, M. Z., \& Goyal, V. K. (2003). Capital structure decisions. [SSRN Working Paper Series no 396020], Social Science Eletronic Publishing, Rochester, New York, USA.

Freeman, C., \& Soete, L. (2008). A economia da inovação industrial. Campinas: UNICAMP.

Geiger, S., \& Makri, M. (2006). Exploration and exploitation innovation processes: the role of organizational slack in R\&D intensive firms. The Journal of High Technology Management Research, 17(1), 97-108.

Gibson, D. V., \& Naquin, H. (2011). Investing in innovation to enable global competitiveness: the case of Portugal. Technological Forecasting and Social Change, 78(8), 1299-1309.

Gifford, S. (1992). Innovation, firm size and growth in a centralized organization. The Rand journal of Economics, 23(2), 284-298.

Gonçalves, C., Filho, Veit, M., \& Monteiro, P. (2013). Inovação, estratégia, orientação para o mercado e empreendedorismo: identificação de clusters de empresas e teste de modelo de predição do desempenho nos negócios. Revista de Administração e Inovação, 10(2), 81-101.

Griliches, Z. (1990). Patent statistics as economic indicators: a survey. Journal of Economic Literature, 28(4), 1661-1707.

Gujarati, D. N., \& Porter, D. C. (2011). Econometria básica. (5a ed.). Porto Alegre: McGraw-Hill.

Guo, S., Hotchkiss, E. S., \& Song, W. (2011). Do buyouts (still) create value?. The Journal of Finance, 66(2), 479-517.

Harris, M., \& Raviv, A. (1991). The theory of capital structure. The Journal of Finance, 46(1), 297-355.

Himmelberg, C., Hubbard, R., \& Palia, D. (1999). Understanding the determinants of managerial ownership and the link between ownership and performance. Journal of Financial Economics, 53(1), 353-384. 
Instituto Brasileiro de Geografia e Estatística - IBGE. (2016). Contas nacionais - 2016. Rio de Janeiro: IBGE. Recuperado em 26 de março de 2017, de www.ibge.gov.br

Jensen, M., \& Meckling, W. H. (1976). Theory of the firm: managerial behavior, agency costs and ownership structure. Journal of Financial Economics, 3(4), 305-360.

Joliet, R., \& Muller, A. (2013). Capital structure effects of international expansion. Journal of Multinational Financial Management, 23(5), 375-393.

Kayo, E. K., \& Famá, R. (2004). A estrutura de capital e o risco das empresas tangível-intensivas e intangível-intensivas. Revista de Administração da Universidade de São Paulo, 39(2), 164-176.

Kayo, E. K., Teh, C. C., \& Basso, L. F. C. (2006). Ativos intangíveis e estrutura de capital: a influência das marcas e patentes sobre o endividamento. Revista de Administração da Universidade de São Paulo, 41(2), 158-168.

Kim, Y. (2015). Environmental, sustainable behaviors and innovation of firms during the financial crisis. Business Strategy and the Environment, 24(1), 58-72.

Knight, G. A., \& Liesch, P. W. (2016). Internationalization: from incremental to born global. Journal of World Business, 51(1), 93-102.

Lai, Y., Lin, F., \& Lin, Y. (2015). Factors affecting firm's R\&D investment decisions. Journal of Business Research, 68(4), 840-844.

Lev, B. (2001). Intangibles: management, measurement, and reporting. Washington: Brookings.

Li, M., \& Simerly, R. L. (2002). Environmental dynamism, capital structure and innovation: an empirical test. The International Journal of Organizational Analysis, 10(2), 156-171.

Magri, S. (2009). The financing of small innovative firms: the Italian case. Economics of Innovation and New Technology, 18(2), 181-206.

March, J. G. (1991). Exploration and exploitation in organizational learning. Organization Science, 2(1), 71-87.

Maroco, J. (2007). Análise estatística - com utilização do SPSS. (3a ed.). Lisboa: Edições Silabo Lda.

MCDougall, P. P., \& Oviatt, B. M. (2000) International entrepreneurship: the intersection of two research paths. Academy of management journal, 43(5), 902-906.

Medeiros, O. R., \& Daher, C. E. (2008). Testando teorias alternativas sobre a estrutura de capital nas empresas brasileiras. Revista de Administração Contemporânea, 12(1), 177-199.

Miller, M. H. (1977). Debt and taxes. Journal of Finance, 32(1), 261-275.

Miranda, K. F., Vasconcelos, A. C., Luca, M. M. M. De, \& Cabral, J. E. O. (2015). A capacidade inovativa e o desempenho econômico-financeiro de empresas inovadoras brasileiras. Revista Eletrônica de Administração, 81(2), 269-299.

Modigliani, F., \& Miller, M. H. (1958). The cost of capital, corporation finance, and the theory of investment. American Economic Review, 48(3), 261-297.

Moura, P. G., \& Galina, S. V. (2009). Empresas internacionalizadas de origem brasileira e a publicação internacional de patentes. Revista de Administração e Inovação, 6(3), 26-45.

Myers, S. C. (1977). Determinants of corporate borrowing. Journal of Financial Economics, 5(1), $147-$ 175.

Myers, S. C. (1984). The capital structure puzzle. The Journal of Finance, 39(3), 574-592.

Myers, S. C., \& Majluf, N. S. (1984). Corporate financing and investment decisions when firms have information investors do not have. Journal of Financial Economics, 13(1), 187-222.

Nhung, L. T. P., \& Okuda, H. (2015). Effects of state ownership on companies' capital structure and profitability: estimation analysis before and after the Lehman shock. Journal of Asian Economics, 38(1), 64-78.

O'brien, J. P. (2003). The capital structure implications of pursuing strategy of innovation. Strategic Management journal, 24(5), 415-431.

OECD - Organisation for Economic Cooperation and Development. (2005). Os/o manual: proposed guidelines for collecting and interpreting technological innovation data. Paris: OECD. 
Pavitt, K. (1982). R\&D, patenting and innovative activities. A statistical exploration. Research Policy, 11(1), 33-51.

Póvoa, L. M. C., \& Nakamura, W. T. (2015). Relevância da estrutura de dívida para os determinantes da estrutura de capital: um estudo com dados em painel. Revista Contemporânea de Contabilidade, $12(25), 3-26$.

Ramos, A., \& Zilber, S. N. (2015). O impacto do investimento na capacidade inovadora da empresa. Revista de Administração e Inovação, 12(1), 303-325.

Santos, J. G. C., Calíope, T., \& Silva Fllho, J. C. (2016). Analisando as diferenças entre investimentos em atividades de inovação conforme variáveis estratégicas contingenciais em empresas de capital aberto no Brasil. Revista Gestão \& Tecnologia, 16(3), 31-57.

Santos, G. F. Z., Hoffmann, M. G., Jara, E. J., \& Coral, E. (2014). Inovação e comportamento setorial: uma análise das empresas participantes do Prêmio Finep de inovação 2010. Revista Eletrônica de Ciência Administrativa, 13(1), 6.

Santos, J. G. C., Vasconcelos, A. C., \& Luca, M. M. M. De. (2013). Perfil da inovação e da internacionalização de empresas transnacionais. Revista de Administração e Inovação, 10(1), 198211.

Santos, J. G. C., Vasconcelos, A. C., \& Luca, M. M. M. De. (2015). Internacionalização e governança corporativa: uma análise das maiores companhias abertas do Brasil pela ótica da economia dos custos de transação. Advances in Scientific and Applied Accounting, 8(3), 300-319.

Segura, L. C., \& Formigoni, H. (2014). Influência do controle e da gestão familiar no endividamento das empresas abertas brasileiras: um estudo quantitativo. Brazilian Business Review, 11(6), 51-76.

Shearmur, R., Doloreux, D., \& Laperrière, A. (2015). Is the degree of internationalization associated with the use of knowledge intensive services or with innovation?. International Business Review, 24(3), 457-465.

Silveira, A. D. M. D., \& Barros, L. A. B. D. C. (2008). Determinantes da qualidade da governança corporativa das companhias abertas brasileiras. Revista Eletrônica de Administração, 14(3), 1-29.

Singh, D. A., \& Gaur, A. S. (2013). Governance structure, innovation and internationalization: evidence from India. Journal of International Management, 19(3), 300-309.

Soares, G. D. O. G., Coutinho, E. S., \& de Camargos, M. A. (2013). Determinantes do rating de crédito de companhias brasileiras. Contabilidade Vista \& Revista, 23(3), 109-143.

Soares, R. O., \& Kloeckner, G. O. Endividamento em firmas com alta propensão à expropriação: 0 caso de firmas com um controlador. Revista de Administração de Empresas, 48(4), 73-96.

Teh, C. C., Kayo, E. K., \& Kimura, H. (2008). Marcas, patentes e criação de valor. Revista de Administração Mackenzie, 9(1), 86-106.

Teixeira, E. A., Nossa, V., \& Funchal, B. (2011). O índice de sustentabilidade empresarial (ISE) e os impactos no endividamento e na percepção de risco. Revista Contabilidade \& Finanças, 22(55), 2944.

Vargas, M. I. R. (2015). Determinant factors for small business to achieve innovation, high performance and competitiveness: organizational learning and leadership style. Procedia-Social and Behavioral Sciences, 169(1), 43-52.

Williamson, O. E. (1988). Corporate finance and corporate governance. The Journal of Finance, 43(3), 567-591.

Yuke, C. H. A. I., \& Xiaomin, G. U. (2015). Study on the relationship between R\&D expenditures, capital structure and enterprise innovation performance. Canadian Social Science, 11(4), 60-67.

Zaltman, G., Duncan, R., \& Holbek, J. (1973). Innovations and organizations. New York: Wiley. 